\title{
Bearing Behavior of H-Shaped Honeycombed Steel Web Composite Columns with Rectangular Concrete-Filled Steel Tube Flanges under Eccentrical Compression Load
}

\author{
Jing Ji, ${ }^{1,2}$ Chenyu Yu, ${ }^{1}$ Liangqin Jiang, ${ }^{1,2}$ Jiedong Zhan, ${ }^{1}$ Hongguo Ren $\left(\mathbb{D},{ }^{3}\right.$ Sixue Hao, ${ }^{3}$ \\ Shaojie Fan $\left(\mathbb{0},{ }^{3}\right.$ Li Jiang, ${ }^{1}$ Yubo Lin, ${ }^{1}$ and Lingjie $\mathrm{He}^{1}$ \\ ${ }^{1}$ College of Civil and Architectural Engineering, Northeast Petroleum University, \\ Heilongjiang Key Laboratory of Disaster Prevention, Mitigation and Protection Engineering, No. 99 Xuefu Road, \\ Longfeng District, Daqing 163318, China \\ ${ }^{2}$ Key Laboratory of Earthquake Engineering and Engineering Vibration, Institute of Engineering Mechanics, \\ China Earthquake Administration, No. 29 Xuefu Road, Nangang District, Harbin 150000, China \\ ${ }^{3}$ Handan Key Laboratory of Building Physical Environment and Regional Building Protection Technology, \\ School of Architecture and Art, Hebei University of Engineering, No. 19 Taiji Road, \\ Handan Economic and Technological Development District, Handan 056038, China
}

Correspondence should be addressed to Hongguo Ren; renhongguo771126@163.com and Shaojie Fan; fanshaojie2021@163.com Received 2 November 2021; Accepted 15 December 2021; Published 5 January 2022

Academic Editor: Lingkun Chen

Copyright (C) 2022 Jing Ji et al. This is an open access article distributed under the Creative Commons Attribution License, which permits unrestricted use, distribution, and reproduction in any medium, provided the original work is properly cited.

\begin{abstract}
In order to investigate the bearing capacity of $\mathrm{H}$-shaped honeycombed steel web composite columns with rectangular concretefilled steel tube flanges (STHCCs) subjected to eccentrical compression load, 33 full-scale STHCCs were designed with the eccentricity $(e)$, the slenderness ratio $(\lambda)$, the cubic compressive strength of concrete $\left(f_{\text {cuk }}\right)$, the thickness of the steel tube flange $\left(t_{1}\right)$, the thickness of honeycombed steel web $\left(t_{2}\right)$, diameter-depth ratio $\left(d / h_{\mathrm{w}}\right)$, space-depth $\left(s / h_{\mathrm{w}}\right)$, and the yield strength of the steel tube $\left(f_{\mathrm{y}}\right)$ as the main parameters. Considering the nonlinear constitutive model of concrete and simplified constitutive model of steel, the finite element (FE) model of STHCCs was established by ABAQUS software. By comparison with the existing test results, the rationality of the constitutive model of materials and FE modeling was verified. The numerical simulation of 33 full-scale STHCCs was conducted, and the influence of different parameters on the ultimate eccentrical compression bearing capacity was discussed. The results show that the cross-sectional stress distribution basically conforms to the plane-section assumption. With the increase in $e, \lambda$, and $d / h_{\mathrm{w}}$, the ultimate eccentrical compression bearing capacity of the full-scale STHCCs decreases, whereas it gradually increases with the increase in $f_{\text {cuk }}, t_{1}, t_{2}, s / h_{\mathrm{w}}$, and $f_{\mathrm{y}}$. By introducing bias-stress stability coefficient $(\varphi)$, the calculation formula of full-scale STHCCs under eccentrical compression is proposed by statistical regression, which can lay a foundation for the popularization and application of these types of composite columns in practical engineering.
\end{abstract}

\section{Introduction}

$\mathrm{H}$-shaped honeycombed steel web composite columns with rectangular concrete-filled steel tube flanges (STHCCs) are types of novel composite members formed by connecting two concrete-filled rectangular steel tubular flanges with a honeycombed steel web. The core concrete can prevent and delay the local buckling of the steel tube and the instability failure of the specimens effectively, and on the other hand, the confinement of the steel tube makes the core concrete in a state of triaxial compression, which can effectively improve the capacity of resisting deformation and the compressive strength of the core concrete. In particular, the honeycombed steel web connects the two limbs into an organic whole, which can not only reduce the weight of the structure, but also improve the stiffness and bearing capacity of the composite columns. These types of composite columns are characterized by high ultimate bearing capacity, good 
ductility, and excellent stability bearing capacity, which are superior to ordinary concrete-filled steel tube (CFST) columns and honeycombed columns [1].

Numerous research studies regarding CFST columns and honeycombed columns have been carried out at home and abroad. Jayaganesh et al. [2] conducted tests on 6 square and 6 circular CFST short columns to study the influence of concentric local compression on the structural behavior of CFST columns under axial compression. Ahmed et al. [3] proposed a simplified model of concrete-filled square steel tube columns subjected to axial compression and presented the interaction curve of high-strength square concrete-filled double steel tubular (CFDST) under eccentric loading by establishing the buckling model of CFDST under axial compression and uniaxial bending. Vatulia et al. [4] analyzed the deformation development regularity of concretefilled rectangular steel tube columns with different lengths subjected to eccentrical loading through the integral method and established the calculation mathematical model of eccentrical compression bearing capacity for concrete-filled rectangular steel tube columns. Yu et al. [5] put forward the formula of eccentrical compression bearing capacity of recycled coarse aggregate self-compacting CFST columns based on the experimental studies and analyzed the applicability of the formula in the United States, China, and Japan. Li et al. [6] conducted eccentrical compression tests of L-shaped square CFST columns and established a finite element (FE) model to study the eccentrical compression behavior of this type column and proposed a bearing capacity analysis method of the rectangular concrete-filled stainless steel tubular (CFSST) columns based on the stress yield criterion at the edge of the section base. Rong et al. [7] analyzed the eccentrical compression behavior of concretefilled square steel tube columns with I-shaped CFRP through experimental research and FE simulation, and derived the calculation formula of eccentrical compression bearing capacity of composite columns. Sui et al. [8] investigated the failure mode of 19 multi-element composite T-shaped CFST columns under biaxial eccentrical compression and proposed the simplified calculation formula of eccentrical compression bearing capacity. Chen et al. [9] studied the influence regularity of different parameters on eccentrical compression test of 18 concrete-filled square steel tube columns with spiral stirrups and derived the calculation formula of eccentrical compression bearing capacity of these types of columns. Twenty-one recycled self-compacting concrete-filled circular steel tubular (RSCFCST) columns were tested subjected to eccentric compression by $\mathrm{Yu}$ et al. [10], and bearing capacity of these kinds of composite columns under eccentric compression was obtained systemically; finally, an analytical model for predicting the effective stiffness of RSCFCST columns under eccentric compression was proposed based on the moment magnifier method. In 2017, Ji et al. [11] investigated the eigenvalue buckling behavior of 29 STHCCs by ABAQUS software. Based on this, in 2018, Ji et al. [12] carried out the research on the overall nonlinear stability of STHCCs and derived the calculation expression of nonlinear stability bearing capacity of STHCCs. In the same year, in order to investigate the influence regularity of different parameters on the axial compression bearing capacity of STHCCs, Ji et al. $[13,14]$ designed and conducted the axial compression tests of 16 short STHCCs and proposed the calculation expression of axial compression bearing capacity for STHCCs. In 2020, Ji et al. [15] studied the eccentrical compression behavior of 17 reduced-scale STHCCs by ABAQUS software and derived the calculation expression of eccentrical compression bearing capacity of reduced-scale STHCCs.

At present, the research on STHCCs is mainly aimed at axial compression and stability behavior, and few studies have been performed on the eccentrical compression behavior of such full-scale columns. Based on the existing axial compression test and results of reduced-scale eccentrical compression behavior of STHCCs, the numerical simulation analysis of 33 full-scale STHCCs is further carried out by ABAQUS software. The influence of different parameters on the ultimate bearing capacity of these types of full-scale composite columns under eccentrical compression is discussed. The calculation formula of eccentrical compression bearing capacity of these types of columns can be obtained by statistical regression based on the simulation results, which can provide technical support for the subsequent research and application of these types of columns.

\section{Specimens Design}

In order to investigate the mechanical behavior of full-scale $\mathrm{H}$-shaped honeycombed steel web composite columns with rectangular concrete-filled steel tube flanges (STHCCs) under eccentrical compression, 33 full-scale STHCCs were designed with the eccentricity $(e)$, the slenderness ratio $(\lambda)$, the cubic compressive strength of concrete $\left(f_{\text {cuk }}\right)$, the thickness of the steel tube flange $\left(t_{1}\right)$, the thickness of honeycombed steel web $\left(t_{2}\right)$, diameter-depth ratio $\left(d / h_{\mathrm{w}}\right)$, space-depth $\left(s / h_{\mathrm{w}}\right)$, and the yield strength of the steel tube $\left(f_{\mathrm{y}}\right)$ as the main parameters. The schematic diagram and specific parameters of the specimens are shown in Figure 1 and Table 1, where $h_{\mathrm{w}}$ represents the width of webs, $d$ refers to the diameter of the honeycombed holes on the web, and $s$ represents the distance between two honeycombed holes.

\section{Finite Element Model}

\subsection{Constitutive Model for Materials}

3.1.1. Constitutive Model for Steel. The stress-strain curve of steel consists of five stages of elastic, elastic-plastic, plastic, strengthening, and second plastic flow. Thirty-three STHCCs designed are all medium-long columns; hence, the strengthening stage of steel can be neglected. The ideal elastoplastic constitutive model is applied to characterize the elastoplastic behavior of steel, as shown in Figure 2(a). Poisson's ratio of steel is set as 0.3 .

3.1.2. Constitutive Model for Concrete. Han [16], Pagoulatou et al. [17], Teng et al. [18], Mander et al. [19], and Qian et al. [20] have successively given the constitutive models of confined concrete, and the constitutive model of unconfined 


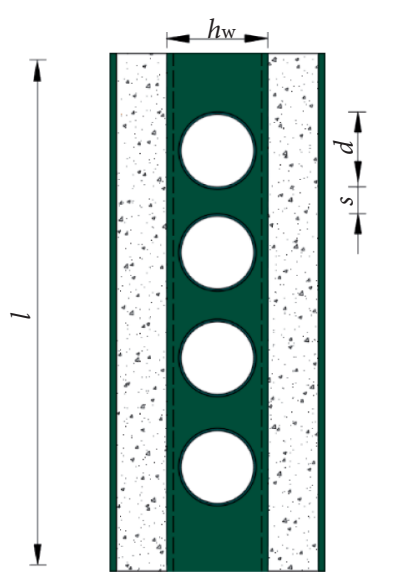

(a)

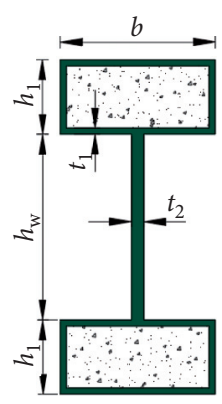

(b)

FIgURe 1: Physical meaning of all variables for STHCC specimens. (a) Longitudinal-section of STHCC specimens. (b) Cross section of STHCC specimens.

TABLE 1: Specific parameters of 33 STHCC specimens.

\begin{tabular}{|c|c|c|c|c|c|c|c|c|c|}
\hline Specimens & $h_{\mathrm{w}} \times h_{1} \times b \times t_{1} \times t_{2}(\mathrm{~mm})$ & $l(\mathrm{~mm})$ & $\lambda$ & $e(\mathrm{~mm})$ & $\xi$ & $f_{\text {cuk }}(\mathrm{MPa})$ & $f_{\mathrm{y}}(\mathrm{MPa})$ & $d / h_{\mathrm{w}}$ & $s / h_{\mathrm{w}}$ \\
\hline STHCC-1 & $400 \times 320 \times 500 \times 8 \times 10$ & 2240 & 19.40 & 80 & 0.73 & 40 & 345 & 0.6 & 0.4 \\
\hline STHCC-2 & $400 \times 320 \times 500 \times 8 \times 10$ & 2240 & 19.40 & 160 & 0.73 & 40 & 345 & 0.6 & 0.4 \\
\hline STHCC-3 & $400 \times 320 \times 500 \times 8 \times 10$ & 2240 & 19.40 & 240 & 0.73 & 40 & 345 & 0.6 & 0.4 \\
\hline STHCC-4 & $400 \times 320 \times 500 \times 8 \times 10$ & 2240 & 19.40 & 320 & 0.73 & 40 & 345 & 0.6 & 0.4 \\
\hline STHCC-5 & $400 \times 320 \times 500 \times 8 \times 10$ & 2240 & 19.40 & 400 & 0.73 & 40 & 345 & 0.6 & 0.4 \\
\hline STHCC-6 & $400 \times 320 \times 500 \times 8 \times 10$ & 3040 & 26.33 & 240 & 0.73 & 40 & 345 & 0.6 & 0.4 \\
\hline STHCC-7 & $400 \times 320 \times 500 \times 8 \times 10$ & 4640 & 40.18 & 240 & 0.73 & 40 & 345 & 0.6 & 0.4 \\
\hline STHCC-8 & $400 \times 320 \times 500 \times 8 \times 10$ & 6240 & 54.04 & 240 & 0.73 & 40 & 345 & 0.6 & 0.4 \\
\hline STHCC-9 & $400 \times 320 \times 500 \times 8 \times 10$ & 7040 & 60.97 & 240 & 0.73 & 40 & 345 & 0.6 & 0.4 \\
\hline STHCC-10 & $400 \times 320 \times 500 \times 8 \times 10$ & 3040 & 26.33 & 240 & 0.98 & 30 & 345 & 0.6 & 0.4 \\
\hline STHCC-11 & $400 \times 320 \times 500 \times 8 \times 10$ & 3040 & 26.33 & 240 & 0.59 & 50 & 345 & 0.6 & 0.4 \\
\hline STHCC-12 & $400 \times 320 \times 500 \times 8 \times 10$ & 3040 & 26.33 & 240 & 0.49 & 60 & 345 & 0.6 & 0.4 \\
\hline STHCC-13 & $400 \times 320 \times 500 \times 8 \times 10$ & 3040 & 26.33 & 240 & 0.42 & 70 & 345 & 0.6 & 0.4 \\
\hline STHCC-14 & $400 \times 320 \times 500 \times 6 \times 10$ & 3040 & 26.33 & 240 & 0.54 & 40 & 345 & 0.6 & 0.4 \\
\hline STHCC-15 & $400 \times 320 \times 500 \times 10 \times 10$ & 3040 & 26.33 & 240 & 0.93 & 40 & 345 & 0.6 & 0.4 \\
\hline STHCC-16 & $400 \times 320 \times 500 \times 12 \times 10$ & 3040 & 26.33 & 240 & 1.14 & 40 & 345 & 0.6 & 0.4 \\
\hline STHCC-17 & $400 \times 320 \times 500 \times 14 \times 10$ & 3040 & 26.33 & 240 & 1.35 & 40 & 345 & 0.6 & 0.4 \\
\hline STHCC-18 & $400 \times 320 \times 500 \times 8 \times 8$ & 3040 & 26.33 & 240 & 0.73 & 40 & 345 & 0.6 & 0.4 \\
\hline STHCC-19 & $400 \times 320 \times 500 \times 8 \times 12$ & 3040 & 26.33 & 240 & 0.73 & 40 & 345 & 0.6 & 0.4 \\
\hline STHCC-20 & $400 \times 320 \times 500 \times 8 \times 14$ & 3040 & 26.33 & 240 & 0.73 & 40 & 345 & 0.6 & 0.4 \\
\hline STHCC-21 & $400 \times 320 \times 500 \times 8 \times 16$ & 3040 & 26.33 & 240 & 0.73 & 40 & 345 & 0.6 & 0.4 \\
\hline STHCC-22 & $400 \times 320 \times 500 \times 8 \times 10$ & 3040 & 26.33 & 240 & 0.73 & 40 & 345 & 0.1 & 0.4 \\
\hline STHCC-23 & $400 \times 320 \times 500 \times 8 \times 10$ & 3040 & 26.33 & 240 & 0.73 & 40 & 345 & 0.3 & 0.4 \\
\hline STHCC-24 & $400 \times 320 \times 500 \times 8 \times 10$ & 3040 & 26.33 & 240 & 0.73 & 40 & 345 & 0.475 & 0.4 \\
\hline STHCC-25 & $400 \times 320 \times 500 \times 8 \times 10$ & 3040 & 26.33 & 240 & 0.73 & 40 & 345 & 0.75 & 0.4 \\
\hline STHCC-26 & $400 \times 320 \times 500 \times 8 \times 10$ & 3040 & 26.33 & 240 & 0.73 & 40 & 345 & 0.6 & 0.15 \\
\hline STHCC-27 & $400 \times 320 \times 500 \times 8 \times 10$ & 3040 & 26.33 & 240 & 0.73 & 40 & 345 & 0.6 & 0.6 \\
\hline STHCC-28 & $400 \times 320 \times 500 \times 8 \times 10$ & 3040 & 26.33 & 240 & 0.73 & 40 & 345 & 0.6 & 0.9 \\
\hline STHCC-29 & $400 \times 320 \times 500 \times 8 \times 10$ & 3040 & 26.33 & 240 & 0.73 & 40 & 345 & 0.6 & 1.4 \\
\hline STHCC-30 & $400 \times 320 \times 500 \times 8 \times 10$ & 3040 & 26.33 & 240 & 0.73 & 40 & 235 & 0.6 & 0.4 \\
\hline STHCC-31 & $400 \times 320 \times 500 \times 8 \times 10$ & 3040 & 26.33 & 240 & 0.73 & 40 & 390 & 0.6 & 0.4 \\
\hline STHCC-32 & $400 \times 320 \times 500 \times 8 \times 10$ & 3040 & 26.33 & 240 & 0.73 & 40 & 420 & 0.6 & 0.4 \\
\hline STHCC-33 & $400 \times 320 \times 500 \times 8 \times 10$ & 3040 & 26.33 & 240 & 0.73 & 40 & 460 & 0.6 & 0.4 \\
\hline
\end{tabular}

concrete has been given in the Chinese Code for Design of Concrete Structures (GB50010-2010) [21]. The comparisons of different constitutive models are illustrated in Figure 2(b). Through comparative analysis, the constitutive model proposed by Han [16], which considered the confinement effect, is applied in this article. It can be seen that the ductility of concrete is improved significantly; nevertheless, the strength of concrete remains unchanged.

The following formula represents the stress-strain curve of concrete under uniaxial compression: 

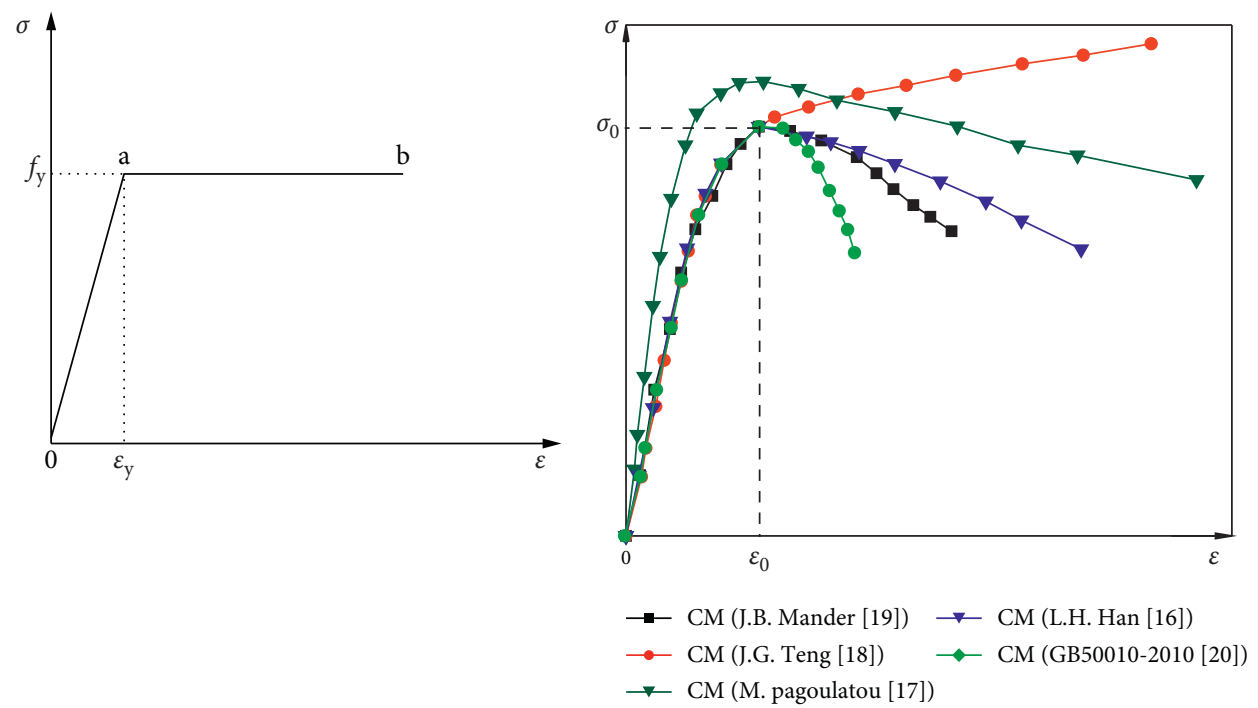

(a)

(b)

Figure 2: Constitutive models. (a) Constitutive model of steel. (b) Constitutive models of concrete.

$$
y= \begin{cases}2 x-x^{2}, & (x \leq 1), \\ \frac{x}{\beta_{0}(x-1)^{(1.6+1.5 / x)}+x}, & (x>1),\end{cases}
$$

where $x=\varepsilon / \varepsilon_{0}, \quad y=\sigma / \sigma_{0}, \sigma_{0}=f_{c}, \quad \varepsilon_{0}=\left(1300+12.5 f_{c}\right) \times$ $10^{-6}+800 \xi^{0.2} \times 10^{-6}$.

The following formula represents the stress-strain curve of concrete under uniaxial tensile:

$$
y= \begin{cases}1.2 x-0.2 x^{6}, & (x \leq 1), \\ \frac{x}{0.31 \sigma_{p}^{2} \cdot(x-1)^{1.7}+x}, & (x>1),\end{cases}
$$

where $\quad x=\varepsilon_{c} / \varepsilon_{p}, \quad y=\sigma_{c} / \sigma_{p}, \sigma_{p}=0.26 \times\left(1.25 f_{c}\right)^{2 / 3}$, $\varepsilon_{p}=43.1 \sigma_{p}$, and other variables can be found in reference [16].

3.2. Modeling Process and Boundary Conditions. The FE models of STHCCs were established by ABAQUS software [22], as shown in Figure 3. By adding material properties and then assigning material properties to the members, the constitutive model proposed by Han can be input into the material of ABAQUS. The eight-joint hexahedral elementtype C3D8R was used to simulate the rectangular steel tube, honeycomb steel web, and concrete. The nonlinear symmetrical contact between steel tube and concrete was simplified as normal hard contact and tangential friction contact, and the Coulomb friction coefficient $(\mu)[23]$ was set as 0.25 . Two reference points were set at the center of the upper and lower surfaces of the columns, namely, RP1 and RP2. The reference points were, respectively, coupled with the top end and the bottom end of the columns. The displacements $\left(U_{\mathrm{x}}, U_{\mathrm{y}}, U R_{\mathrm{x}}, U R_{\mathrm{y}}\right)$ of the top end for columns were constrained by RP1, and the displacements $\left(U_{\mathrm{x}}, U_{\mathrm{y}}, U_{\mathrm{z}}\right.$,

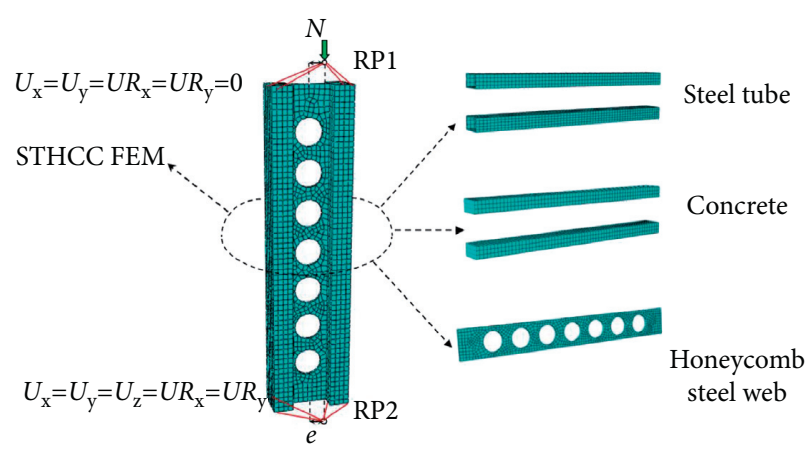

FIgure 3: The FE models of STHCCs.

$\left.U R_{\mathrm{x}}, U R_{\mathrm{y}}\right)$ of the bottom end for columns were constrained by RP2.

\section{Experimental Verification of FE Models}

In order to verify the rationality of the FE models, numerical simulation analysis on 4 specimens selected from reference [24] and 11 specimens selected from references [25-28] was carried out, as shown in Table 2. The load-lateral deflection curves of the mid-span sections and failure modes were obtained. By the comparison, it could be seen from Figure 4 that the curves obtained by the simulation were consistent with the test curves. The comparisons of the bearing capacity obtained by simulation $\left(N_{a}\right)$ and the bearing capacity by test $\left(N_{t}\right)$ were shown in Figure 5. The maximum error was $8.74 \%$, which could meet the requirements of engineering accuracy. The rationality of FE modeling proposed in this article was verified.

\section{Parameter Analysis of Full-Scale STHCCs}

According to the proposed FE model, the load $(N)$-vertical displacement $(\Delta)$ curves, the load $(N)$-lateral deflection $(\Delta)$ curves of the mid-span sections, and the $N / N_{\mathrm{u}}-M / M_{\mathrm{u}}$ curves 
TABLE 2: : The specific parameters of 15 specimens.

\begin{tabular}{|c|c|c|c|c|c|c|c|c|}
\hline Specimens & $L(\mathrm{~mm})$ & $e(\mathrm{~mm})$ & $f_{\text {cuk }}(\mathrm{MPa})$ & $f_{\mathrm{y}}(\mathrm{Mpa})$ & $N_{t}(\mathrm{kN})$ & $N_{a}(\mathrm{kN})$ & $\left\|N_{a}-N_{t} / N_{t}\right\| \times 100 \%$ & \\
\hline \multirow{4}{*}{ The tests conducted by $\mathrm{Li}$ et al. [24] } & GZ-1 & 866 & 25.0 & 45.3 & 314 & 1411 & 1416.8 & 0.41 \\
\hline & GZ-2 & 866 & 50.0 & 63.9 & 314 & 1236 & 1216.3 & 1.59 \\
\hline & GZ-3 & 1300 & 25.0 & 63.9 & 314 & 1365 & 1381.1 & 1.18 \\
\hline & GZ-4 & 1300 & 50.0 & 84.7 & 314 & 1150 & 1198.2 & 4.19 \\
\hline \multirow[t]{11}{*}{ The tests conducted by Du et al. [25-28] } & $\begin{array}{c}\text { SC40-150- } \\
0.2\end{array}$ & 1180 & 13.0 & 43.2 & 488.4 & 2470 & 2576.11 & 4.30 \\
\hline & $\begin{array}{c}\text { SC40-180- } \\
0.2\end{array}$ & 1180 & 18.5 & 43.2 & 488.4 & 2660 & 2520.53 & 5.24 \\
\hline & $\begin{array}{c}\text { SC40-200- } \\
0.2\end{array}$ & 1180 & 20.0 & 43.2 & 488.4 & 2595 & 2445.86 & 5.75 \\
\hline & $\begin{array}{c}\text { SC50-150- } \\
0.2\end{array}$ & 1180 & 15.0 & 55.3 & 488.4 & 2450 & 2664.10 & 8.74 \\
\hline & $\begin{array}{c}\text { SC50-180- } \\
0.2\end{array}$ & 1180 & 18.0 & 55.3 & 488.4 & 2530 & 2684.80 & 6.12 \\
\hline & $\begin{array}{c}\text { SC50-200- } \\
0.2\end{array}$ & 1180 & 19.0 & 55.3 & 488.4 & 2625 & 2608.31 & 0.64 \\
\hline & $\begin{array}{c}\text { SC40-150- } \\
0.4\end{array}$ & 1180 & 31.5 & 43.2 & 488.4 & 2042 & 2032.09 & 0.49 \\
\hline & $\begin{array}{c}\text { SC40-180- } \\
0.4\end{array}$ & 1180 & 37.0 & 43.2 & 488.4 & 2150 & 2074.93 & 3.49 \\
\hline & $\begin{array}{c}\text { SC50-150- } \\
0.4\end{array}$ & 1180 & 32.5 & 55.3 & 488.4 & 2020 & 2127.70 & 5.33 \\
\hline & $\begin{array}{c}\text { SC50-180- } \\
0.4\end{array}$ & 1180 & 41.0 & 55.3 & 488.4 & 2150 & 2104.70 & 2.11 \\
\hline & $\begin{array}{c}\text { SC50-200- } \\
0.4\end{array}$ & 1180 & 41.5 & 55.3 & 488.4 & 2100 & 2091.91 & 0.39 \\
\hline
\end{tabular}

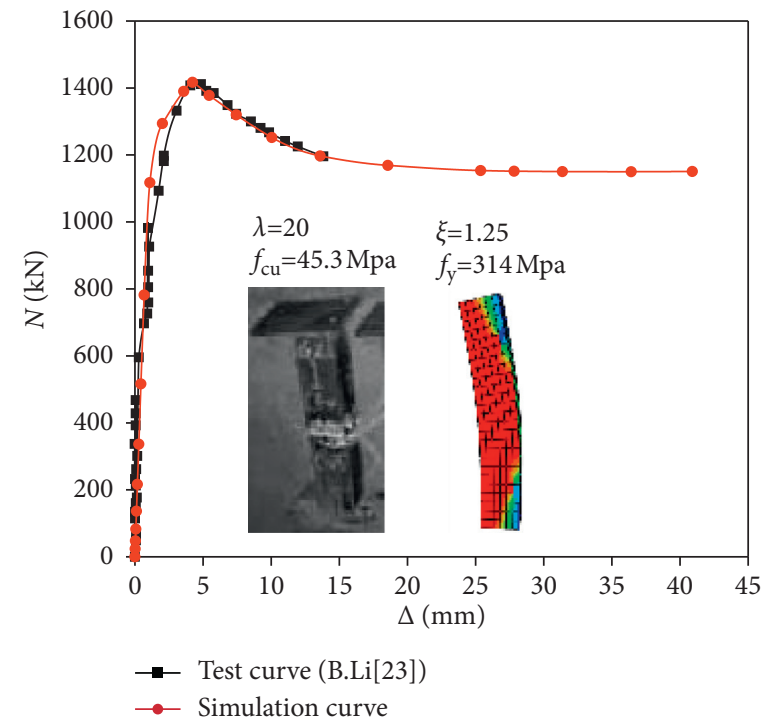

(a)

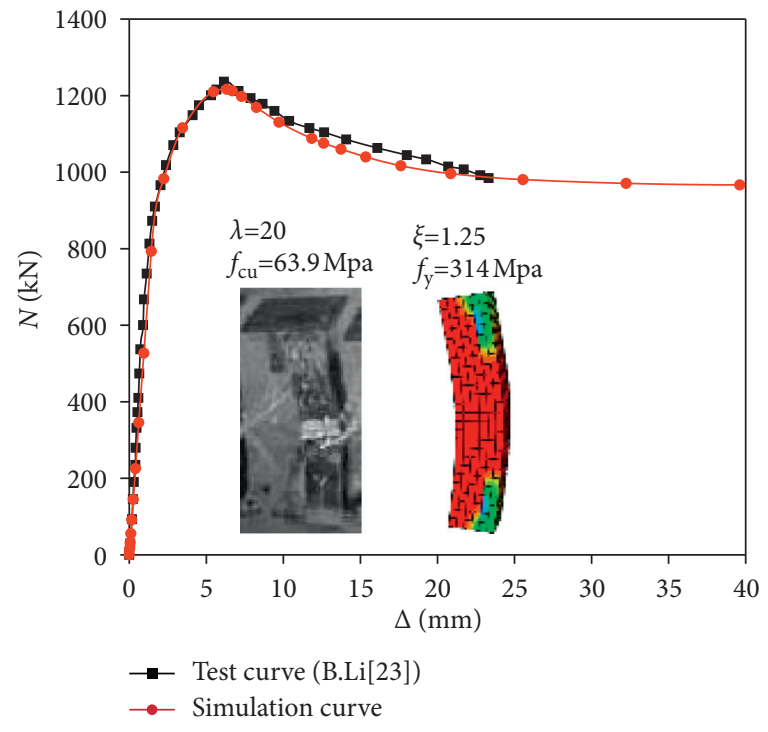

(b)

FIgURE 4: Continued. 


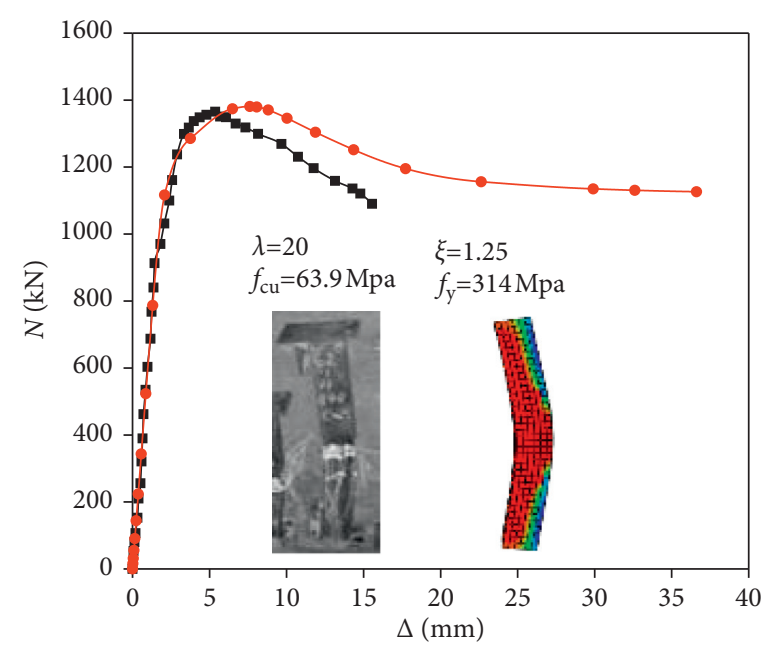

$\rightarrow$ Test curve (B.Li[23])

- Simulation curve

(c)

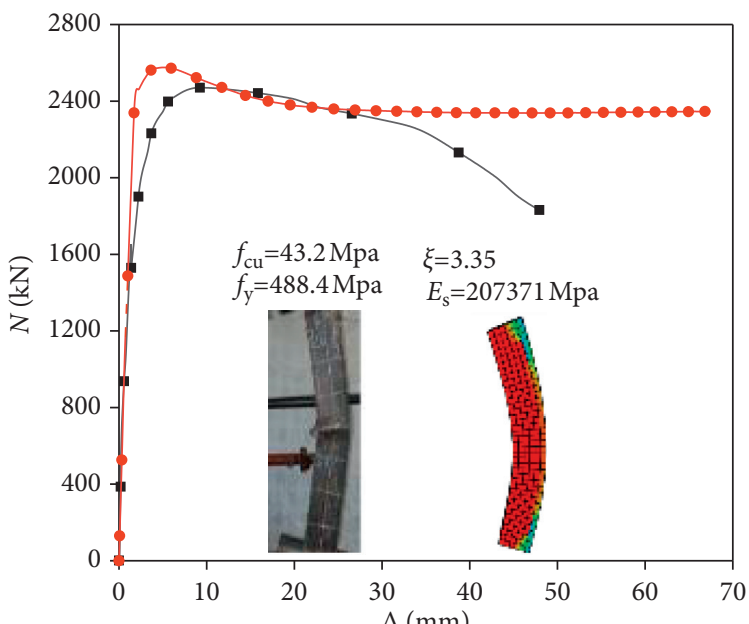

$\rightarrow$ Test curve (Y.S. Du [24-27])

$\rightarrow$ Simulation curve

(e)

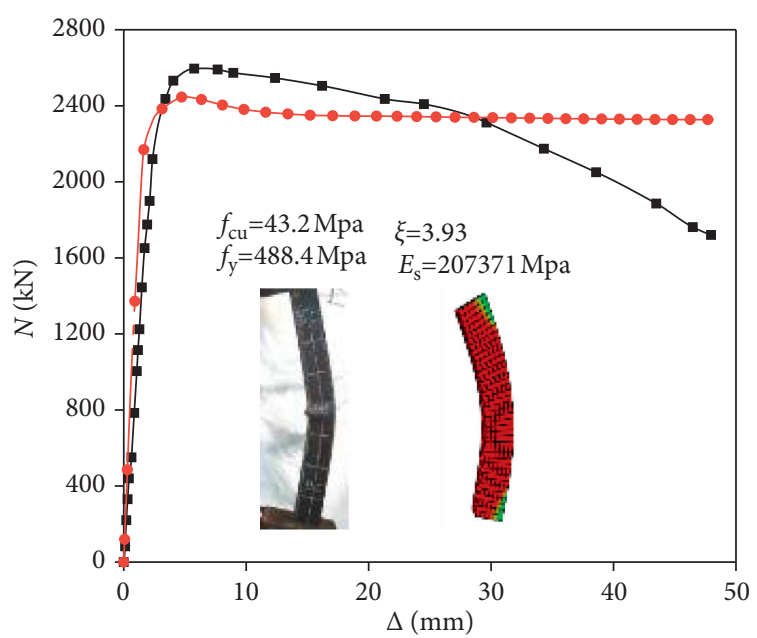

- Test curve (Y.S. Du [24-27])

$\rightarrow$ Simulation curve

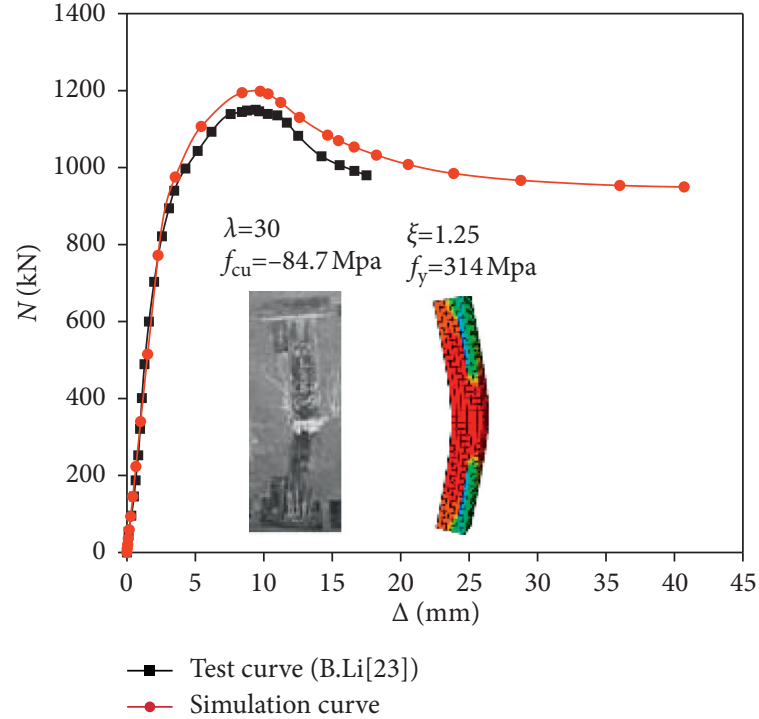

(d)

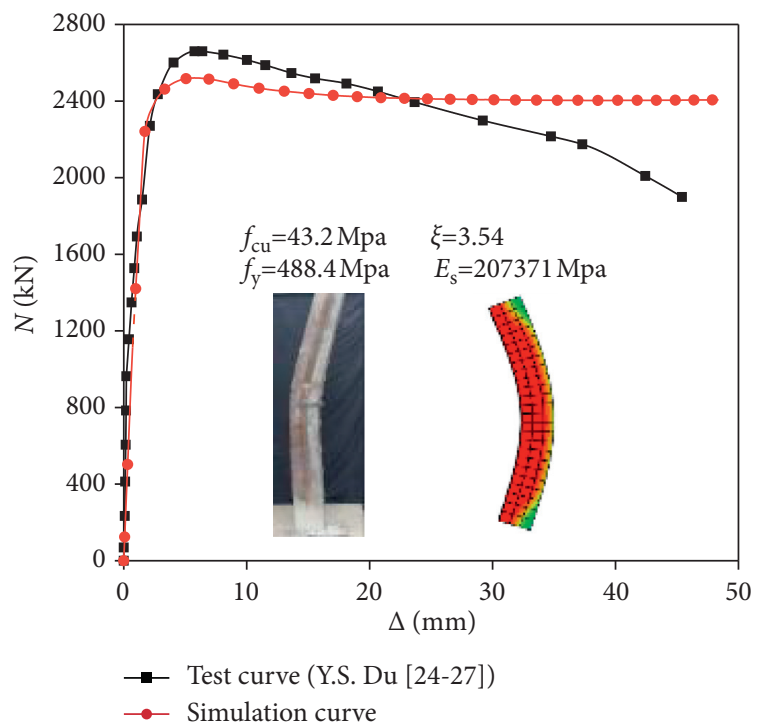

(f)

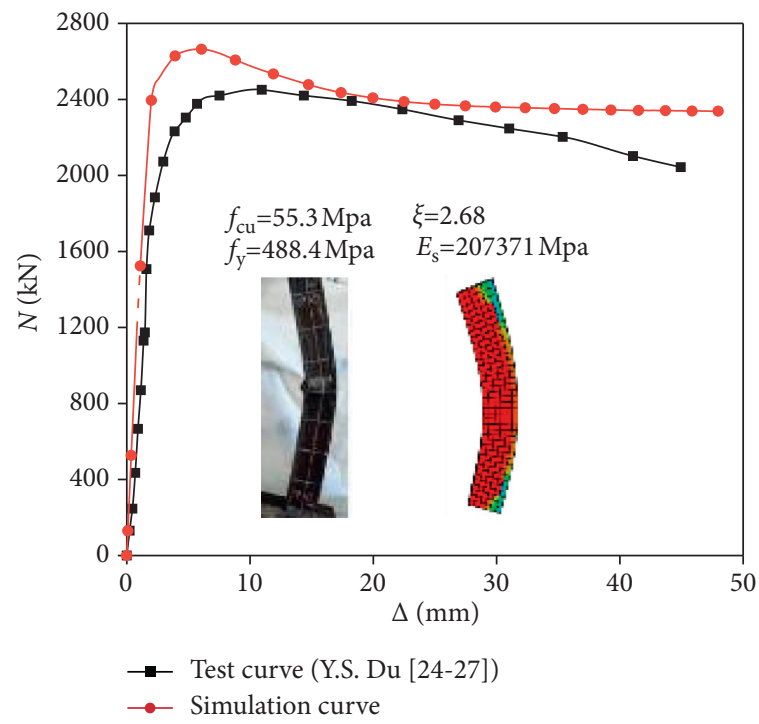

(h)

(g)

Figure 4: Continued. 


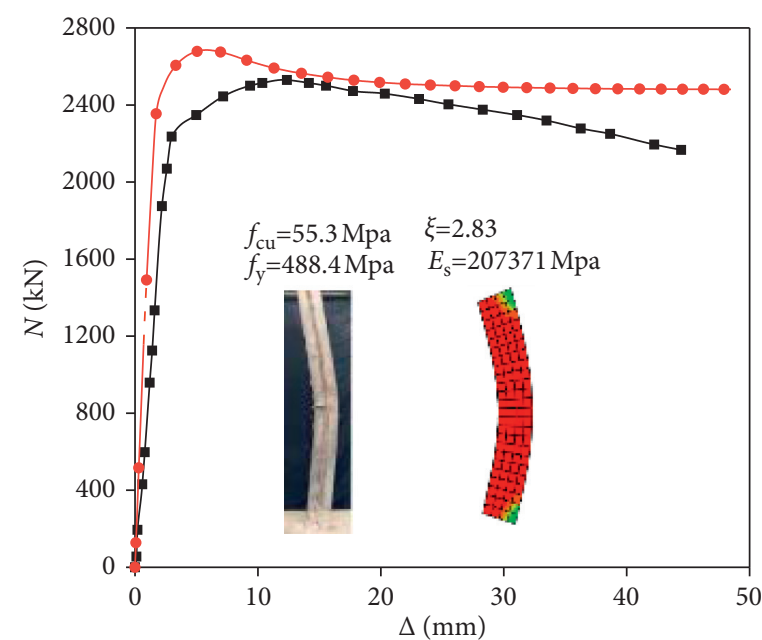

$\rightarrow$ Test curve (Y.S. Du [24-27])

$\rightarrow$ Simulation curve

(i)

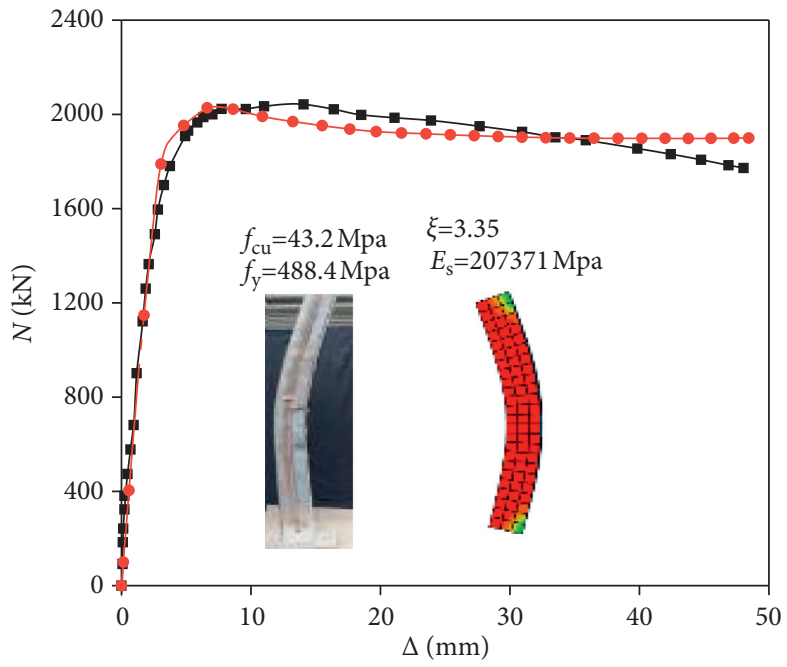

$\rightarrow$ Test curve (Y.S. Du [24-27])

$\rightarrow$ Simulation curve

(k)

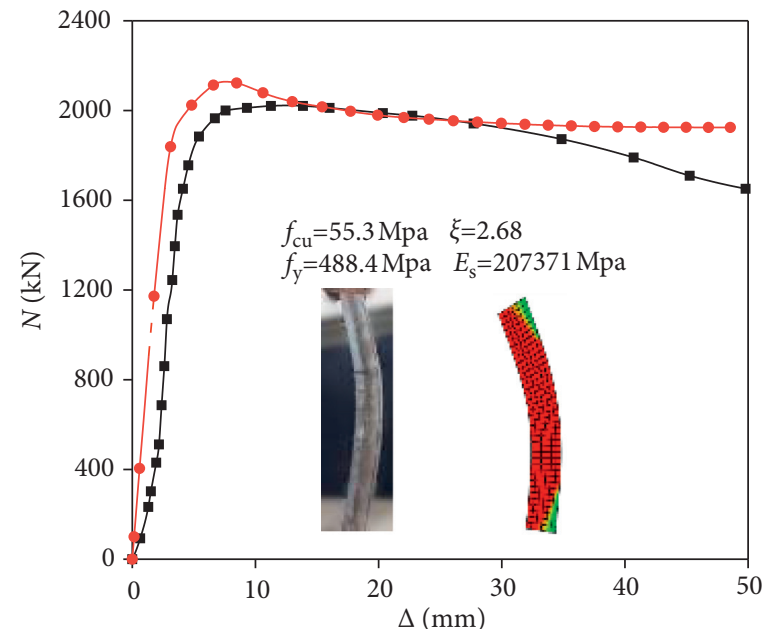

$\rightarrow$ Test curve (Y.S. Du [24-27])

$\rightarrow$ Simulation curve

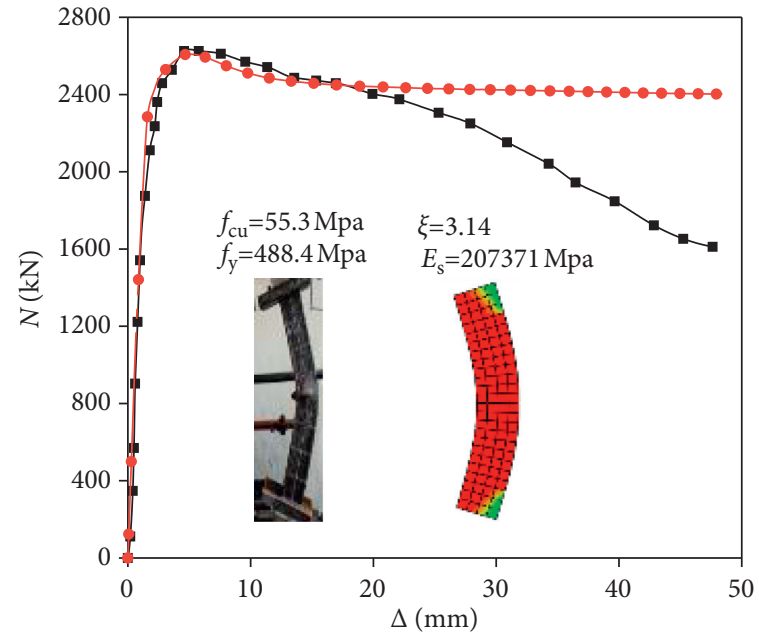

- Test curve (Y.S. Du [24-27])

$\rightarrow$ Simulation curve

(j)

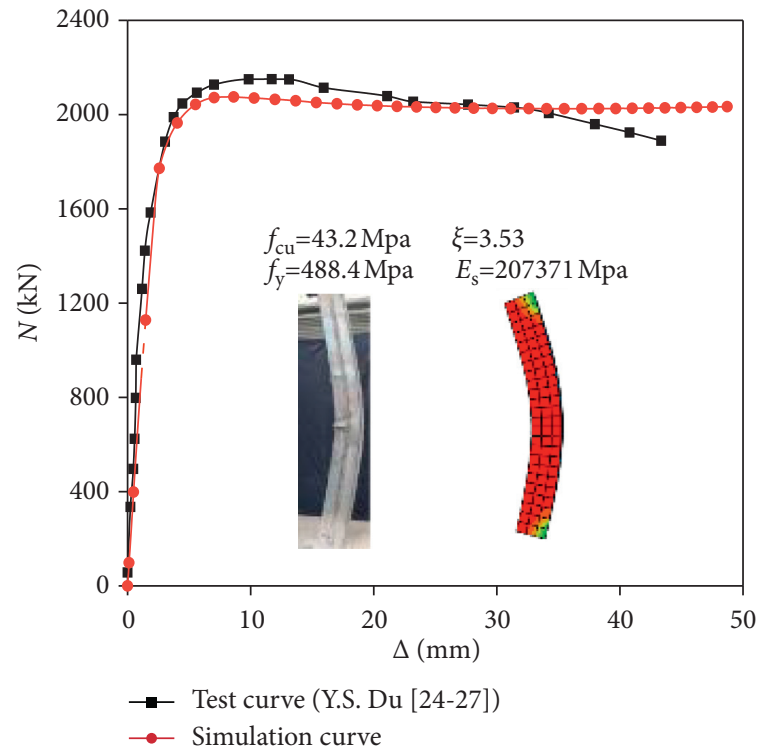

(1)

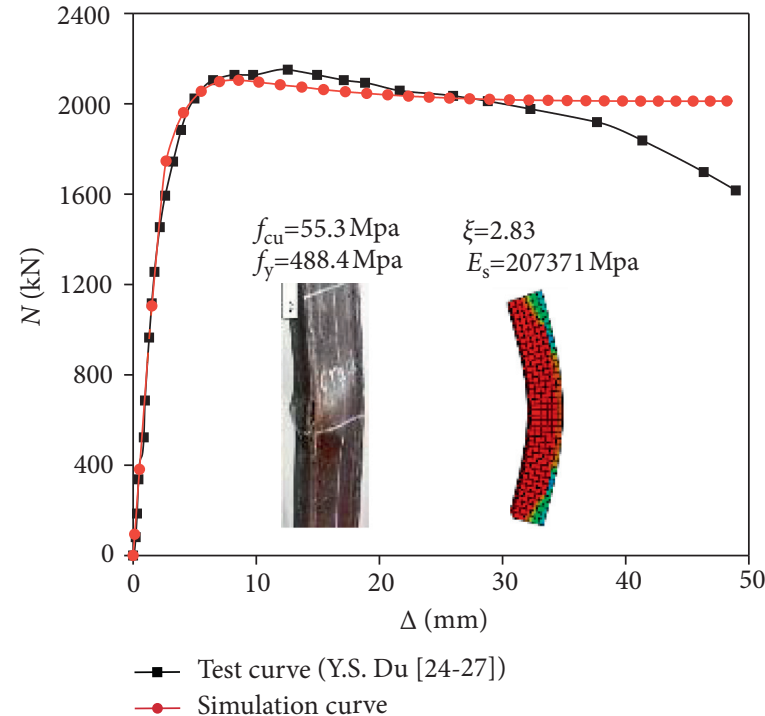

(n) 


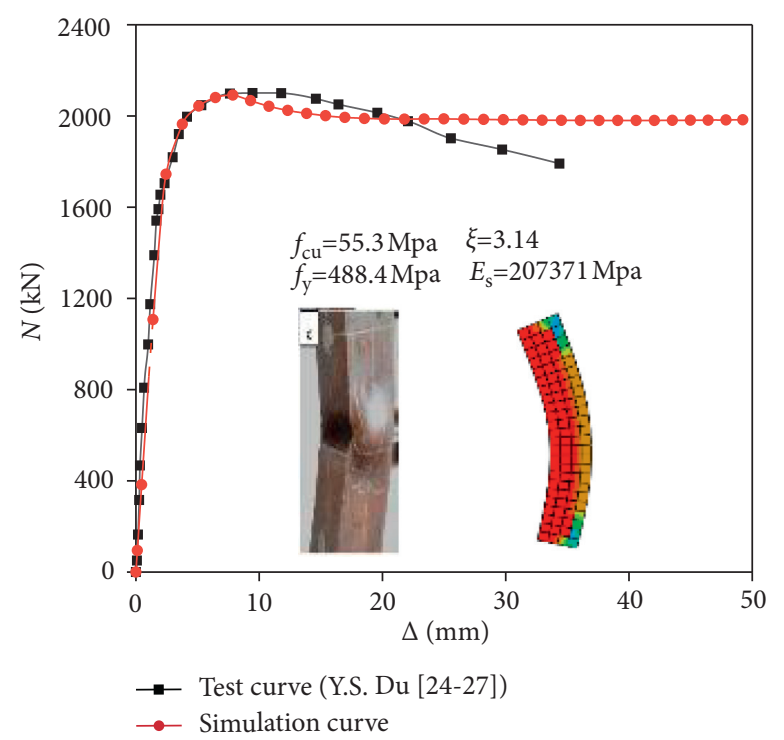

(o)

Figure 4: Comparisons for $N-\Delta$ curves between simulation and test results. (a) GZ-1. (b) GZ-2. (c) GZ-3. (d) GZ-4. (e) SC40-150-0.2. (f) SC40-180-0.2. (g) SC40-200-0.2. (h) SC50-150-0.2. (i) SC50-180-0.2. (j) SC50-200-0.2. (k) SC40-150-0.4. (l) SC40-180-0.4. (m) SC50150-0.4. (n) SC50-180-0.4. (o) SC50-200-0.4.

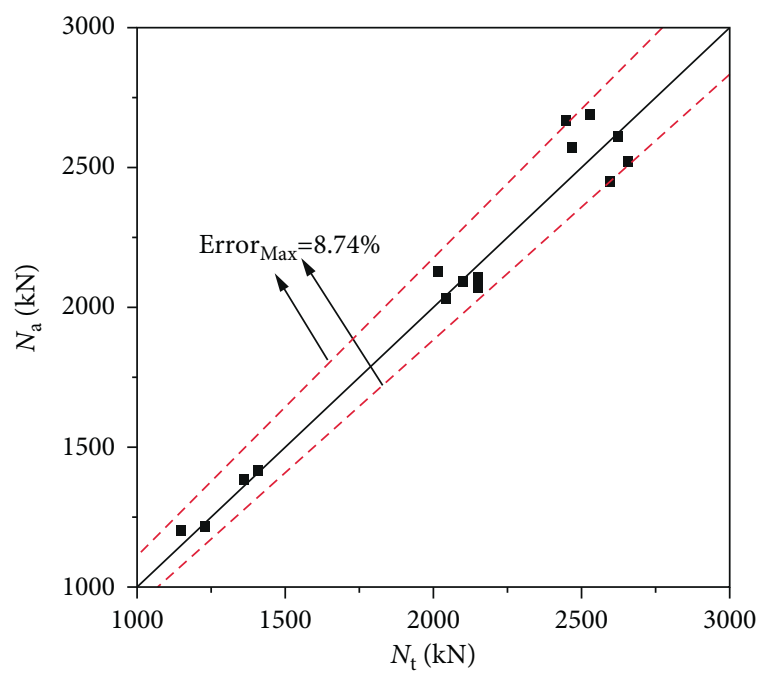

Figure 5: Comparison between $N_{a}$ and $N_{t}$ for 15 STHCCs under eccentrical compression.

for full-scale STHCCs can be computed. Moreover, based on the proposed FE model, the effects of different parameters on the $N-\Delta$ curves were discussed. The main parameters can be summarized as eccentricity $(e)$, the slenderness ratio $(\lambda)$, the cubic compressive strength of concrete $\left(f_{\text {cuk }}\right)$, the thickness of the steel tube flange $\left(t_{1}\right)$, the thickness of honeycombed steel web $\left(t_{2}\right)$, diameter-depth ratio $\left(d / h_{\mathrm{w}}\right)$, space-depth $\left(s / h_{\mathrm{w}}\right)$, and the yield strength of the steel tube $\left(f_{\mathrm{y}}\right)$.

5.1. Load-Vertical Displacement Curves. The load $(N)$-vertical displacement $(\Delta)$ curves of the specimens with different eccentricity, slenderness ratio, and diameter-depth ratio are shown in Figure 6. It can be found that the load $(N)$-vertical displacement $(\Delta)$ curves can be classified into four development stages: elastic stage, elastic-plastic ascending stage, descending stage, and gentle stage. With the increase in the eccentricity, the slenderness ratio, and diameter-depth ratio, the eccentrical compression bearing capacity of the specimens gradually decreases. Figure 6(a) shows the load $(N)$ versus the vertical displacement $(\Delta)$ relationships of the specimens with different eccentricity, and when the eccentricity of the specimens increases from $80 \mathrm{~mm}$ to $400 \mathrm{~mm}$, the initial stiffness of the specimens decreases from $5.06 \times 10^{6} \mathrm{kN} / \mathrm{m}$ to $1.97 \times 10^{6} \mathrm{kN} / \mathrm{m}$, which reduce by $61.1 \%$. The eccentrical compression capacity of the specimens decreases from $17.39 \times 10^{3} \mathrm{kN}$ to $9.9 \times 10^{3} \mathrm{kN}$, which decreases by $42.6 \%$. It indicates that with the increase in the eccentricity, the initial stiffness and eccentrical compression capacity of the specimens decrease. Figure 6(b) shows the load $(N)$ versus the vertical displacement $(\Delta)$ relationships of the specimens with different slenderness ratio, in which as the slenderness ratio of the specimens increases from 19.4 to 60.97, the initial stiffness of the specimens decreases from $3.62 \times 10^{6} \mathrm{kN} / \mathrm{m}$ to $1.17 \times 10^{6} \mathrm{kN} / \mathrm{m}$, which reduces by $67.7 \%$. The eccentrical compression capacity of the specimens decreases from $12.86 \times 10^{3} \mathrm{kN}$ to $10.88 \times 10^{3} \mathrm{kN}$, which decreases by $15.4 \%$, while the decline section of the curves gradually slow down. It indicates that with the increase in the slenderness ratio, the initial stiffness and eccentrical compression capacity of the specimens decrease, whereas the ductility increases. Figure 6(c) shows the load $(N)$ versus the vertical displacement $(\Delta)$ relationships of the specimens with different diameter-depth ratio, and when the diameterdepth ratio of the specimens increases from 0.1 to 0.75 , the eccentrical compression capacity of the specimens decreases from $13.61 \times 10^{3} \mathrm{kN}$ to $11.87 \times 10^{3} \mathrm{kN}$, which decreases by $12.8 \%$, while the decline section of the curves gradually slow down. It can be seen that with the increase in the 


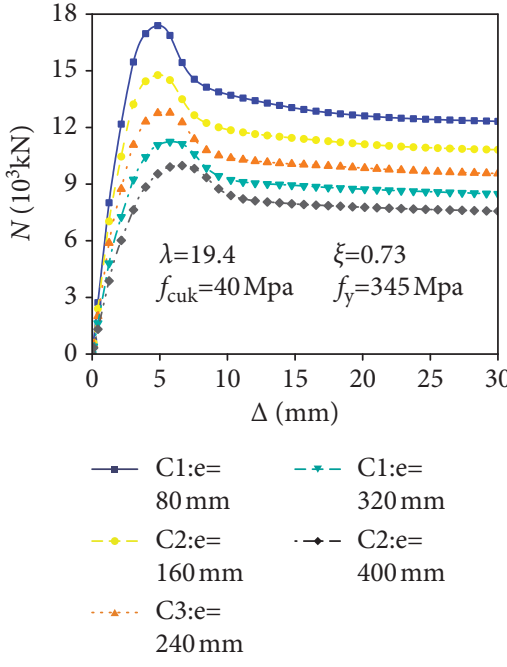

(a)

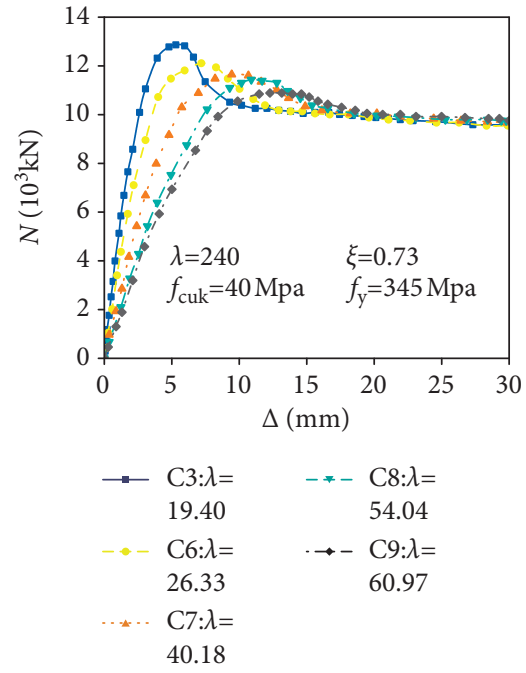

(b)

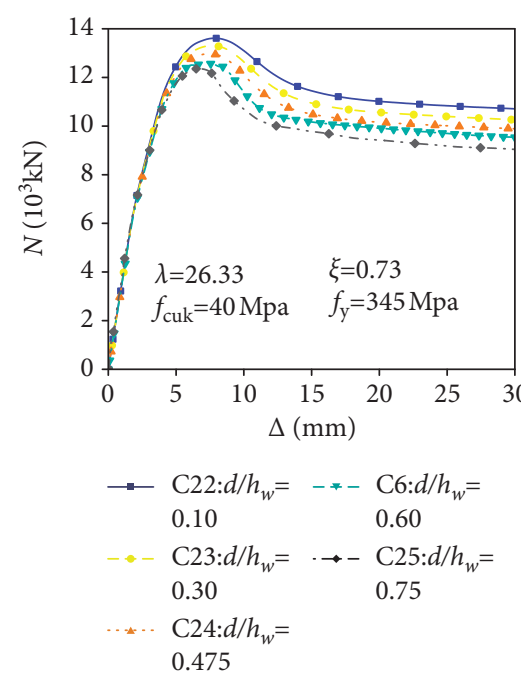

(c)

Figure 6: Comparisons of $N-\Delta$ curves of STHCCs with different parameters. (a) $e$. (b) $\lambda$. (c) $d / h_{\mathrm{w}}$.

diameter-depth ratio, the eccentrical compression bearing capacity of the specimens decreases gradually.

Figure 7 illustrates the load $(N)$ versus the vertical displacement $(\Delta)$ relationships of the specimens with different parameters. Obviously, with the increase in the cubic compressive strength of concrete, the thickness of the steel tube flange, the thickness of honeycombed steel web, spacedepth ratio, and the yield strength of the steel tube, the eccentrical compression bearing capacity of the specimens increases gradually. Figure 7 (a) shows the load $(N)$ versus the vertical displacement $(\Delta)$ relationships of the specimens with different cubic compressive strength of concrete, and when the cubic compressive strength of concrete increases from $30 \mathrm{MPa}$ to $70 \mathrm{MPa}$, the eccentrical compression capacity of the specimens increases from $11.05 \times 10^{3} \mathrm{kN}$ to $17.45 \times 10^{3} \mathrm{kN}$, which raises by $57.92 \%$. It indicates that with the increase in the cubic compressive strength of concrete, the eccentrical compression capacity of the specimens increases. Figure 7(b) shows the load $(N)$ versus the vertical displacement $(\Delta)$ relationships of the specimens with different thickness of the steel tube flange, and when the thickness of the steel tube flange increases from $6 \mathrm{~mm}$ to $14 \mathrm{~mm}$, the eccentrical compression capacity of the specimens increases from $11.37 \times 10^{3} \mathrm{kN}$ to $16.32 \times 10^{3} \mathrm{kN}$, which raises by $43.54 \%$. It reflects that with the increase in the thickness of the steel tube flange, the eccentrical compression capacity of the specimens increases. The load $(N)$ versus the vertical displacement $(\Delta)$ relationships of the specimens with different thickness of honeycombed steel web are illustrated in Figure 7(c), and when the thickness of honeycombed steel web increases from $8 \mathrm{~mm}$ to $16 \mathrm{~mm}$, the eccentrical compression capacity of the specimens increases from $12.38 \times 10^{3} \mathrm{kN}$ to $13.35 \times 10^{3} \mathrm{kN}$, which increases by $7.84 \%$. It can be found that with the increase in the thickness of honeycombed steel web, the eccentrical compression bearing capacity of the specimens increases gradually. Figure $7(\mathrm{~d})$ shows the load $(N)$ versus the vertical displacement $(\Delta)$ relationships of the specimens with different space-depth ratio, and when the space-depth ratio increases from 0.15 to 1.4 , the eccentrical compression capacity of the specimens increases from $12.42 \times 10^{3} \mathrm{kN}$ to $13.12 \times 10^{3} \mathrm{kN}$, which raises by $5.64 \%$, which indicates that with the increase in the space-depth ratio, the eccentrical compression capacity of specimens increases. The load $(N)$ versus the vertical displacement $(\Delta)$ relationships of the specimens with different yield strength of the steel tube are illustrated in Figure 7(e), and when the yield strength of the steel tube increases from $235 \mathrm{MPa}$ to $460 \mathrm{MPa}$, the eccentrical compression capacity of the specimens increases from $10.86 \times 10^{3} \mathrm{kN}$ to $14.51 \times 10^{3} \mathrm{kN}$, which increases by $33.61 \%$. It can be found that with the increase in the yield strength of the steel tube, the eccentrical compression bearing capacity of the specimens increases gradually.

5.2. Load-Lateral Deflection Curves of Mid-span Sections. Figure 8 shows that with the increase in the eccentricity, the cubic compressive strength of concrete, the thickness of the steel tube flange, and diameter-depth ratio, the lateral deflection of mid-span sections of the specimens decreases gradually. The load-lateral deflection curves of the specimens with different parameters are illustrated in Figure 8. As the eccentricity of the specimens increases from $80 \mathrm{~mm}$ to $400 \mathrm{~mm}$, the lateral deflection of mid-span sections decreases from $28.64 \mathrm{~mm}$ to $17.77 \mathrm{~mm}$, which reduces by $37.94 \%$, as shown in Figure 8(a). It can be found that the lateral deflection of mid-span sections of the specimens decreases gradually with the increase in eccentricity. Figure 8(b) illustrates the eccentrical load $(N)$ versus lateral deflection $(\Delta)$ relationships of specimens with different cubic compressive strength of concrete, and as the cubic compressive strength of concrete increases from $30 \mathrm{MPa}$ to $70 \mathrm{MPa}$, the lateral deflection of mid-span sections decreases from $30.16 \mathrm{~mm}$ to $22.32 \mathrm{~mm}$, which reduces by $25.92 \%$. It 


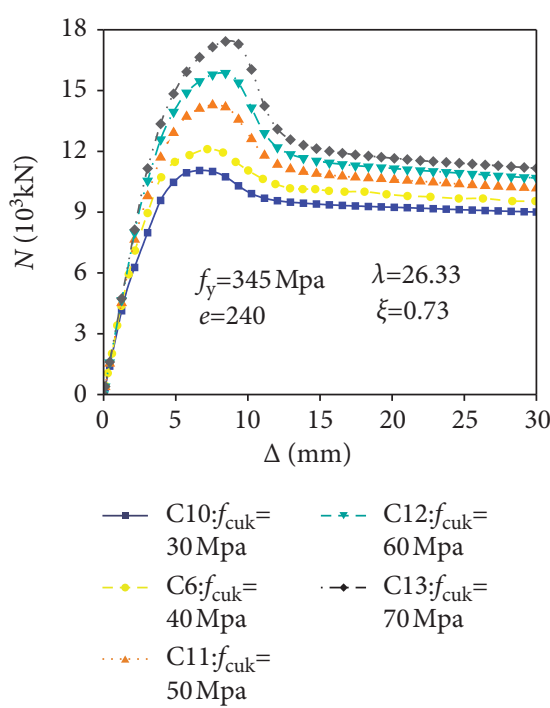

(a)

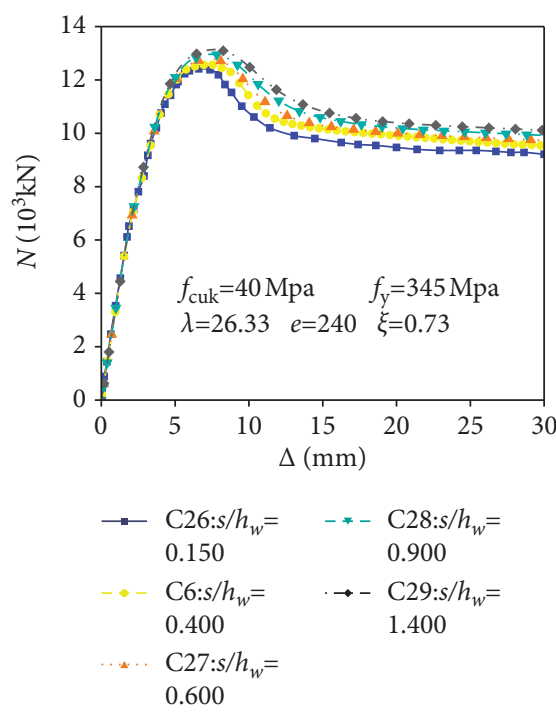

(d)

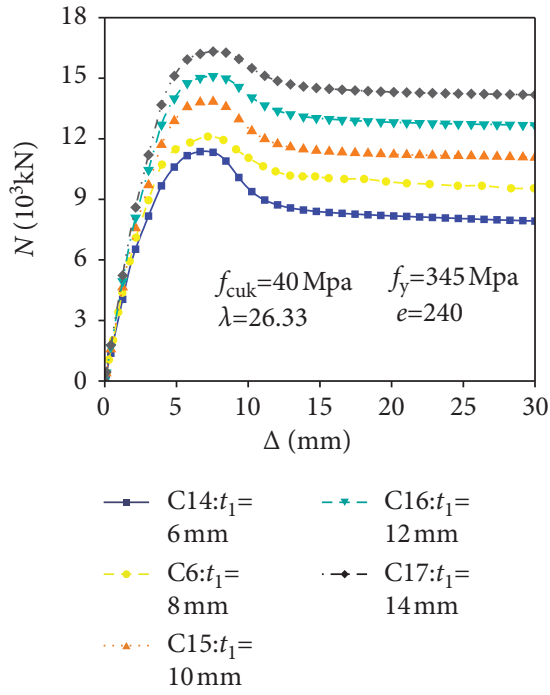

(b)

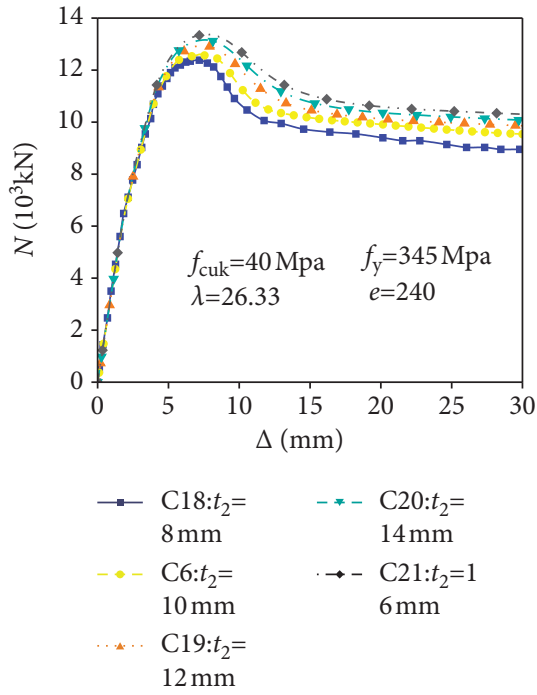

(c)

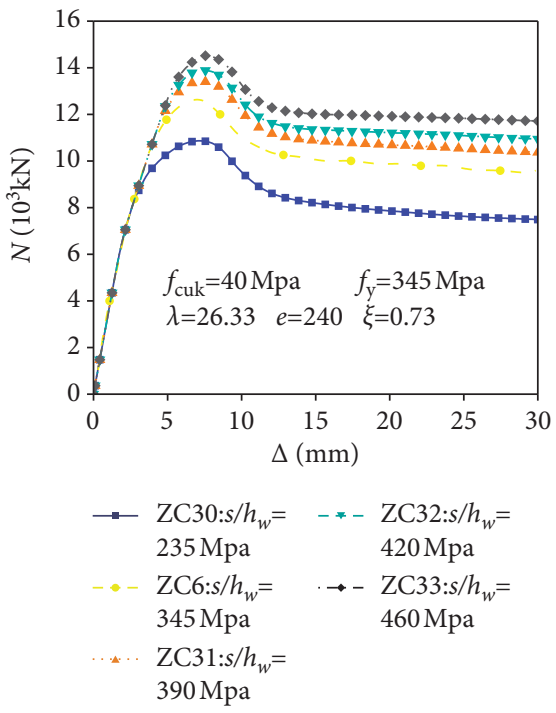

(e)

Figure 7: Comparisons of $N-\Delta$ curves of STHCCs with different parameters. (a) $f_{\text {cuk }}$ (b) $t_{1}$. (c) $t_{2}$. (d) $s / h_{\mathrm{w}}$. (e) $f_{\mathrm{y}}$.

can be found that with the increase in the cubic compressive strength of concrete, the lateral deflection of mid-span sections of the specimens decreases gradually.

Figure 8(c) shows that as the thickness of the steel tube flange increases from $6 \mathrm{~mm}$ to $14 \mathrm{~mm}$, the lateral deflection of mid-span sections decreases from $29.56 \mathrm{~mm}$ to $23.00 \mathrm{~mm}$, which reduces by $22.19 \%$. This indicates that with the increase in the thickness of the steel tube flange, the lateral deflection of mid-span decreases. Figure $8(\mathrm{~d})$ shows that as the diameter-depth ratio increases from 0.1 to 0.75 , the lateral deflection of mid-span sections decreases from $31.21 \mathrm{~mm}$ to $23.83 \mathrm{~mm}$, which reduces by $28.32 \%$. This indicates that with the increase in the diameter-depth ratio, the lateral deflection of mid-span sections of the specimens decreases.

Figure 9 shows that with the increase in the slenderness ratio, the thickness of honeycombed steel web, space-depth ratio, and the yield strength of the steel tube, the lateral deflection of mid-span sections of specimens gradually increases. As the slenderness ratio of the specimens increases from 19.4 to 60.97 , the lateral deflection of mid-span section increases from $21.94 \mathrm{~mm}$ to $53.87 \mathrm{~mm}$, which raises by $145.53 \%$, as shown in Figure 9(a). It can be found that the lateral deflection of mid-span sections of the specimens increases gradually with the increase in the slenderness ratio. Figure 9(b) illustrates the eccentrical load $(N)$ versus lateral deflection $(\Delta)$ relationships of the specimens with different thickness of honeycombed steel web, in which as the thickness of honeycombed steel web increases from $8 \mathrm{~mm}$ to $16 \mathrm{~mm}$, the lateral deflection of mid-span sections increases from $26.36 \mathrm{~mm}$ to $30.23 \mathrm{~mm}$, which raises by $14.68 \%$. It can be found that with the increase in the thickness of honeycombed steel web of the specimens, the lateral deflection of mid-span sections of the specimens decreases gradually. 


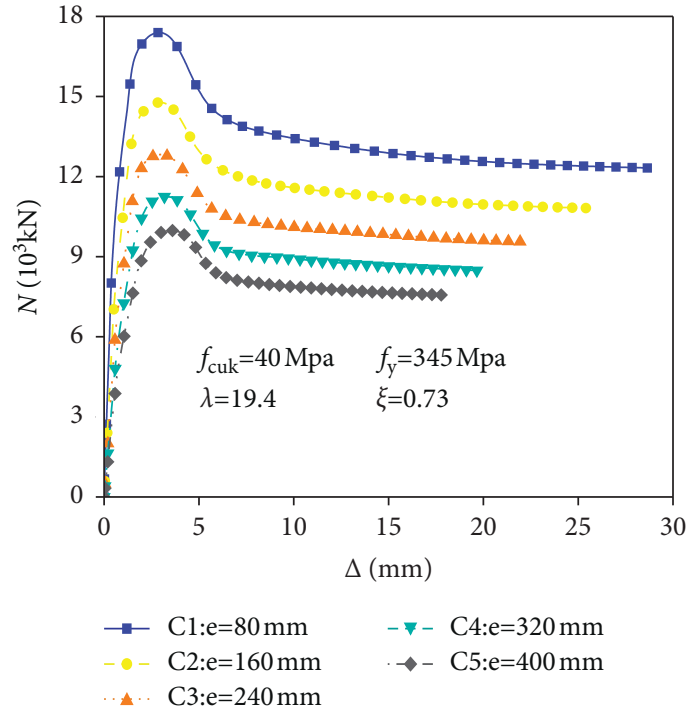

(a)

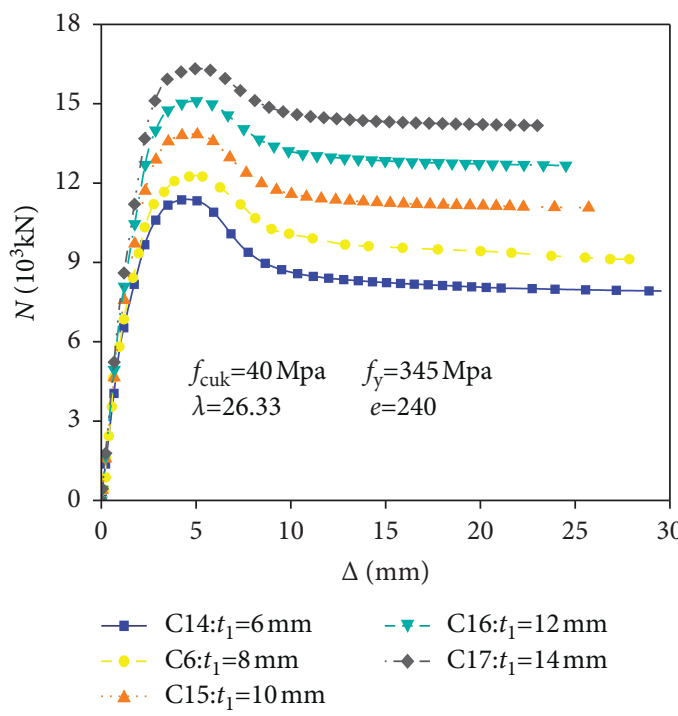

(c)

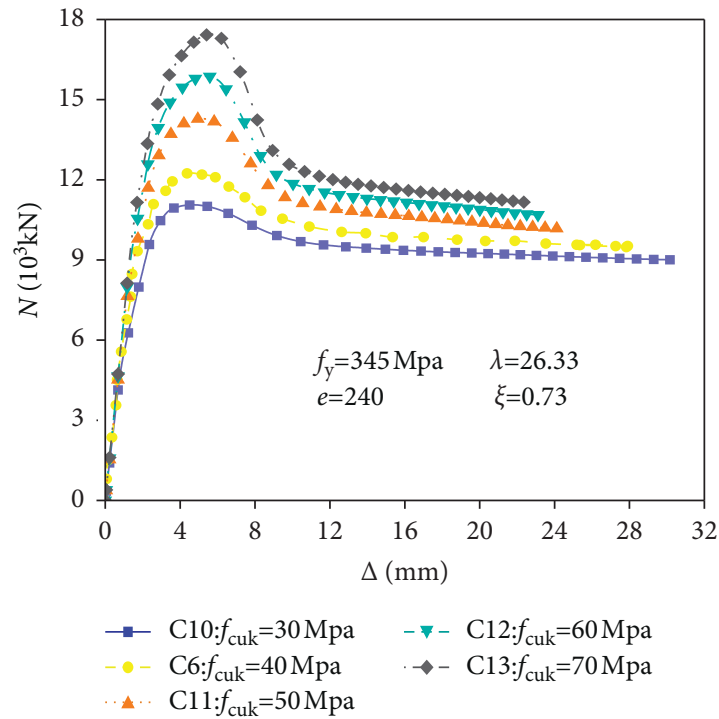

(b)

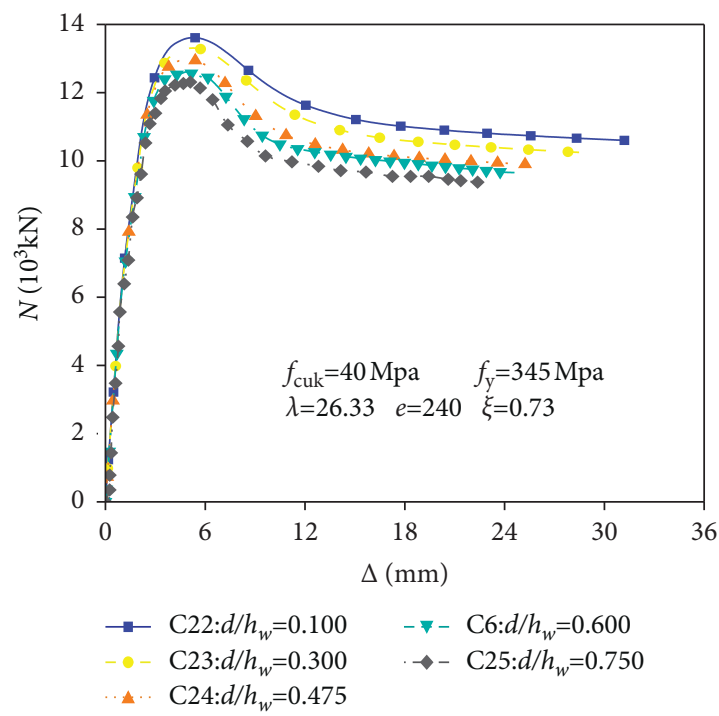

(d)

FIgURE 8: Comparisons of $N-\Delta$ curves of STHCCs with different parameters. (a) $e$. (b) $f_{\text {cuk. }}$ (c) $t_{1}$. (d) $d / h_{\mathrm{w}}$.

Figure 9(c) shows that as the space-depth ratio of the specimens increases from 0.15 to 1.4 , the lateral deflection of mid-span sections increases from $24.36 \mathrm{~mm}$ to $35.67 \mathrm{~mm}$, which improves by $46.43 \%$. It indicates that the lateral deflection of mid-span sections decreases with the increase in the space-depth ratio of the specimens. Figure 9(d) shows that as the yield strength of the steel tube increases from $235 \mathrm{MPa}$ to $460 \mathrm{MPa}$, the lateral deflection of mid-span sections increases from $23.61 \mathrm{~mm}$ to $30.64 \mathrm{~mm}$, which raises by $29.78 \%$. This indicates that the lateral deflection of midspan sections increases with the increase in the yield strength of the steel tube of the specimens.

5.3. $N / N_{u}-M / M_{u}$ Curves. The numerical simulation results of the specimens reflect that with the increase in the slenderness ratio, the thickness of the steel tube flange, and diameter-depth ratio, the convexity of the $N / N_{\mathrm{u}}-M / M_{\mathrm{u}}$ curves of the specimens gradually decreases, as illustrated in Figure 10. With the increase in the cubic compressive strength of concrete, the thickness of honeycombed steel web, space-depth ratio, and the yield strength of the steel tube, the convexity of the $N / N_{\mathrm{u}}-M / M_{\mathrm{u}}$ curves of the specimens gradually increases, as shown in Figure 11, and the load transfer capacity of honeycomb steel web increases.

Figure 10 (a) illustrates that with the increase in the slenderness ratio of the specimens, the convexity of the $N$ / $N_{\mathrm{u}}-M / M_{\mathrm{u}}$ curves of the specimens gradually decreases, and the inflection points of the curves become inconspicuously. The curves basically show a trend to be straight lines, and with the increase in the slenderness ratio of the specimens, the intersection points of the curves and the longitudinal axis close to the origin gradually, which indicates that with the increase in the slenderness ratio of the specimens, the 


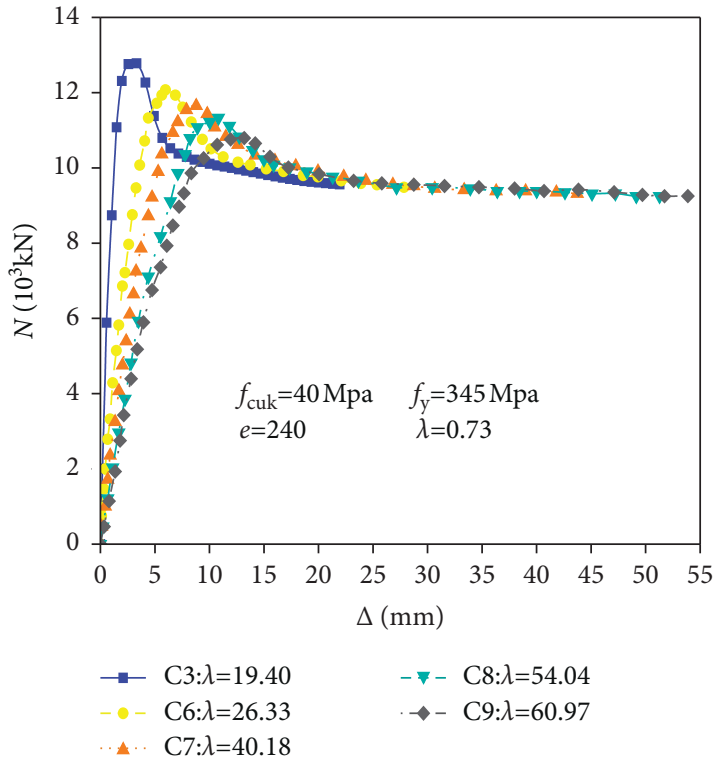

(a)

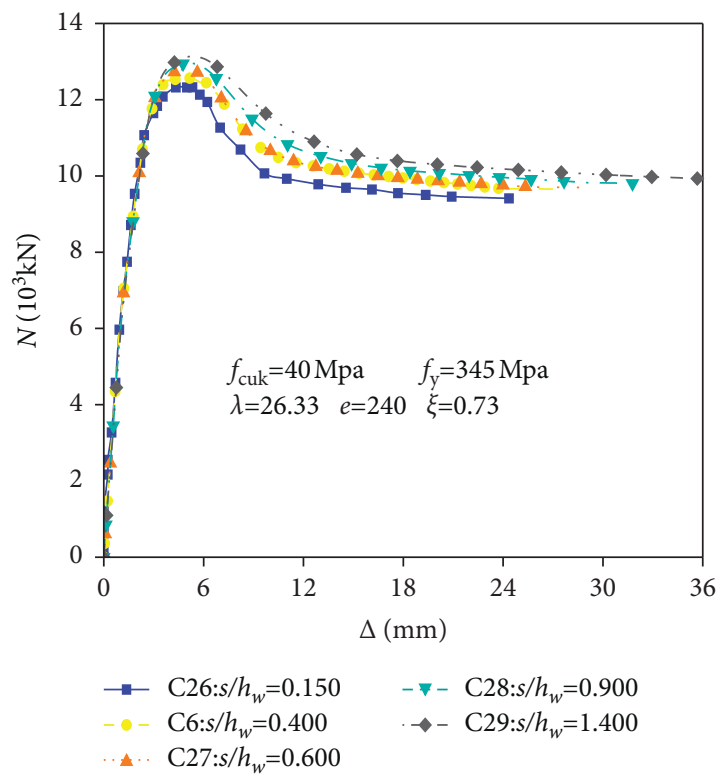

(c)

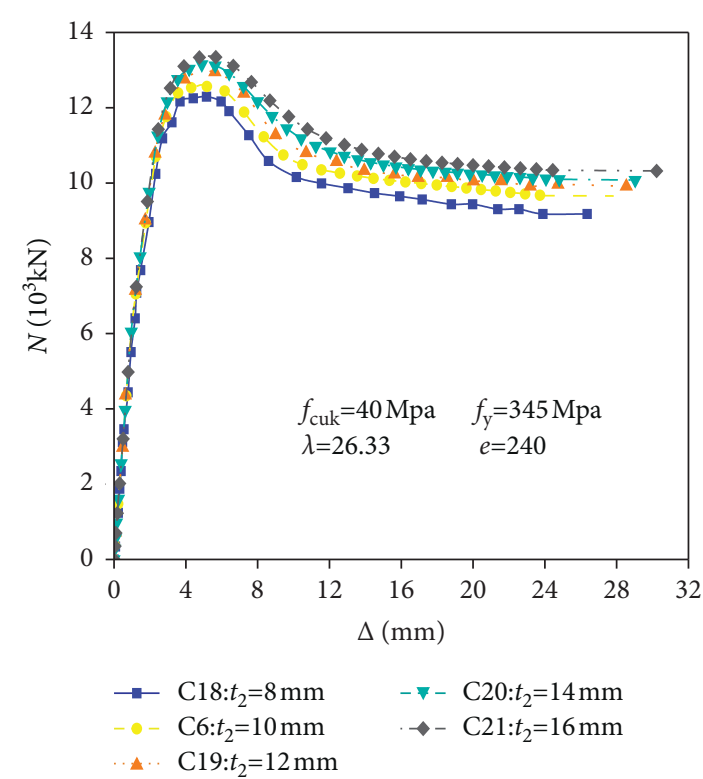

(b)

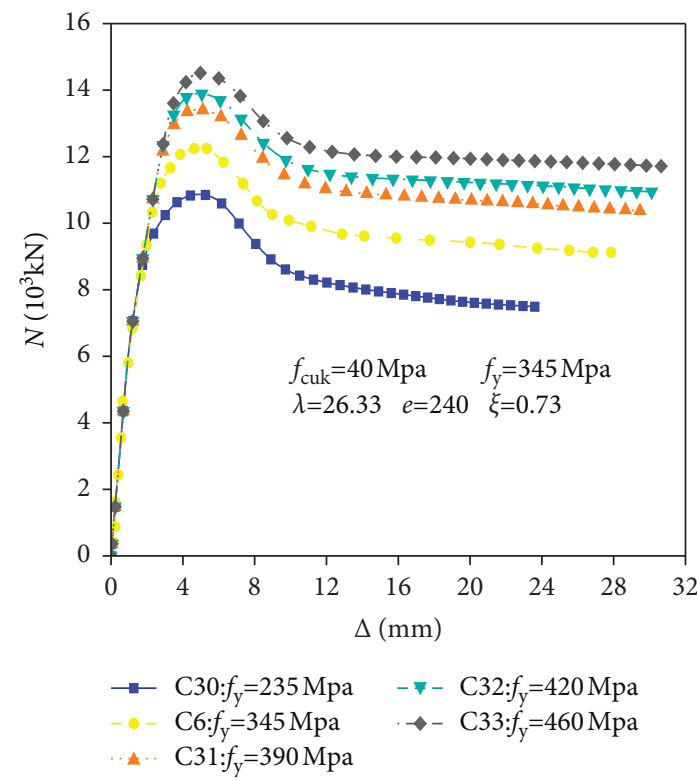

(d)

Figure 9: Comparisons of $N-\Delta$ curves of STHCCs with different parameters. (a) $\lambda$. (b) $t_{2}$. (c) $s / h_{\mathrm{w}}$. (d) $f_{\mathrm{y}}$.

deformation of the specimens becomes larger, and the second-order bending moment caused by the geometric deformation of the specimens increases, and the eccentric compression bearing capacity of the specimens decreases. It can be found from Figure 10(b) that with the increase in the thickness of the flange steel tube, the convexity of the $N / N_{\mathrm{u}^{-}}$ $M / M_{\mathrm{u}}$ curve of the specimens gradually decreases. It can also be found that with the increase in the thickness of the flange steel tube, the constraint effect of the steel tube on the core concrete increases. Figure 10(c) shows that with the increase in the diameter-depth ratio, the convex degree of the $N / N_{\mathrm{u}^{-}}$ $M / M_{\mathrm{u}}$ curve of the specimens decreases gradually. It can be seen that with the increase in the diameter-depth ratio, the inflection point of $N / N_{\mathrm{u}}-M / M_{\mathrm{u}}$ curve moves left, which indicates that the load transfer capacity of honeycomb steel web decreases with the decrease in the diameter-depth ratio.

Figure 11(a) shows that with the increase in the cubic compressive strength of concrete, the convexity of the $N / N_{\mathrm{u}}$ $M / M_{\mathrm{u}}$ curves of the specimens gradually increases. It can be seen that with the increase in the cubic compressive strength of concrete of the specimens, the constraint effect of the steel tube on the core concrete decreases. It can be found from Figure 11(b) that with the increase in the thickness of the honeycomb steel web of the specimens, the convexity of the $N / N_{\mathrm{u}}-M / M_{\mathrm{u}}$ curves of the specimens gradually increases. It can also be found that with the increase in the thickness of 


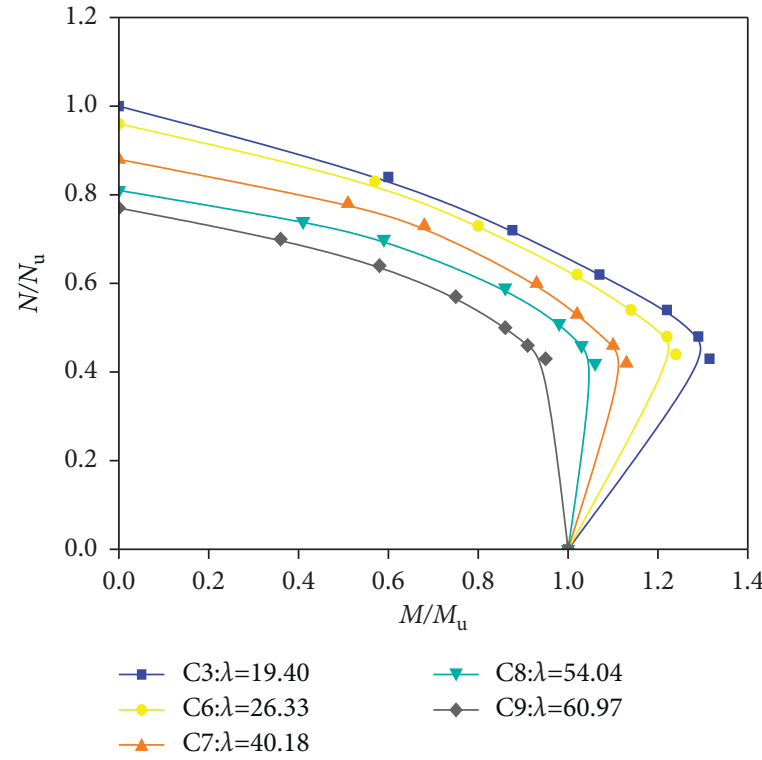

(a)

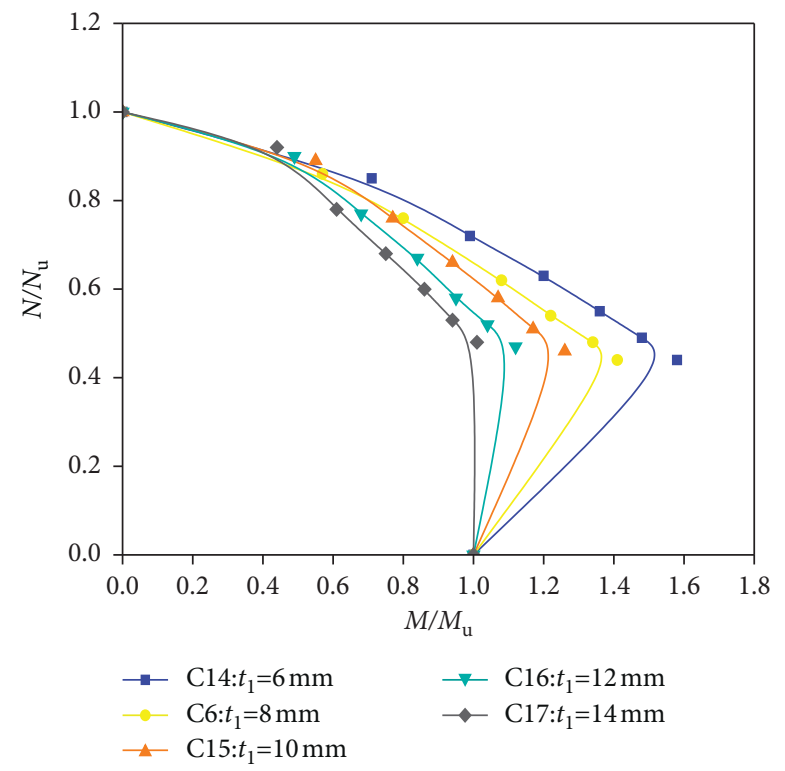

(b)

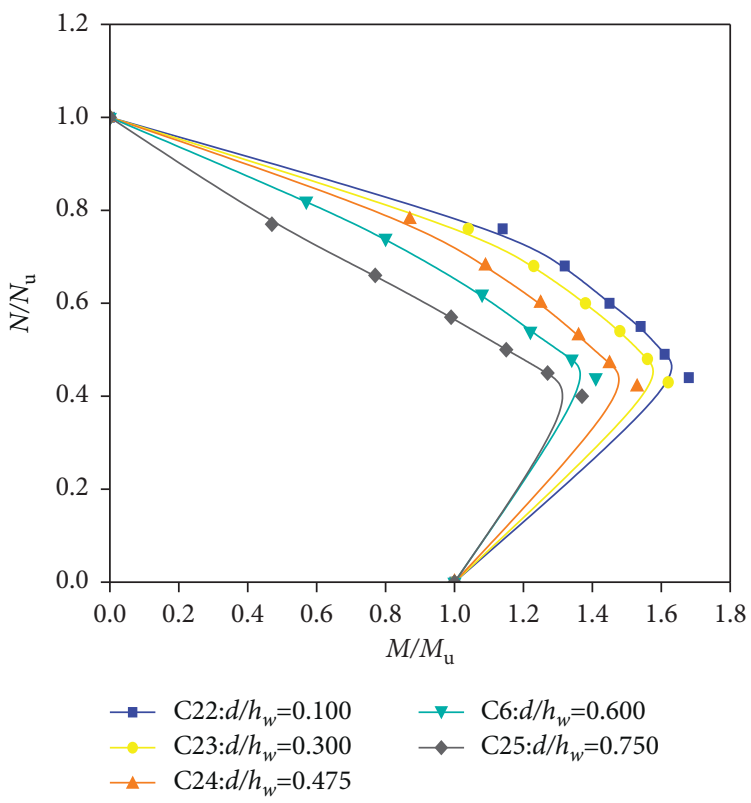

(c)

Figure 10: Comparisons of $N / N_{\mathrm{u}}-M / M_{\mathrm{u}}$ curves of STHCCs with different parameters. (a) $\lambda$. (b) $t_{1}$. (c) $d / h_{\mathrm{w}}$.

the honeycomb steel web, the ability of load transfer of the honeycomb steel web increases, and the inflection points of the $N / N_{\mathrm{u}}-M / M_{\mathrm{u}}$ curves move upward.

As can be seen from Figure 11(c), the convexity of the N/ $N_{\mathrm{u}}-M / M_{\mathrm{u}}$ curves of the specimens increases with the increase in the space-depth ratio, which shows that with the increase in the distance-to-height ratio, the capacity of load transfer of the honeycomb steel web increases. Figure 11(d) illustrates that with the increase in the yield strength of the steel tube, the convex degree of $N / N_{\mathrm{u}}-M / M_{\mathrm{u}}$ curves of the specimens increases gradually, which indicates that with the increase in the yield strength of the steel tube, the constraint effect of the steel tube on concrete increases obviously.

\section{Force Mechanism of Full-Scale STHCCs under Eccentrical Compression}

6.1. Lateral Deflection Curves. Five full-scale specimens are selected from 33 STHCCs as representative examples, and the representative specimens exhibit different eccentricity. The lateral $(H)$-deflection $(\Delta)$ curves of the five specimens subjected to eccentrical compression are shown in Figure 12. It is noteworthy that the $H-\Delta$ curves of the specimens are basically symmetrical distribution. The maximum deflection appears at the mid-span sections of the specimens, and the increase in the deflection is proportional to the increase in the eccentricity. 


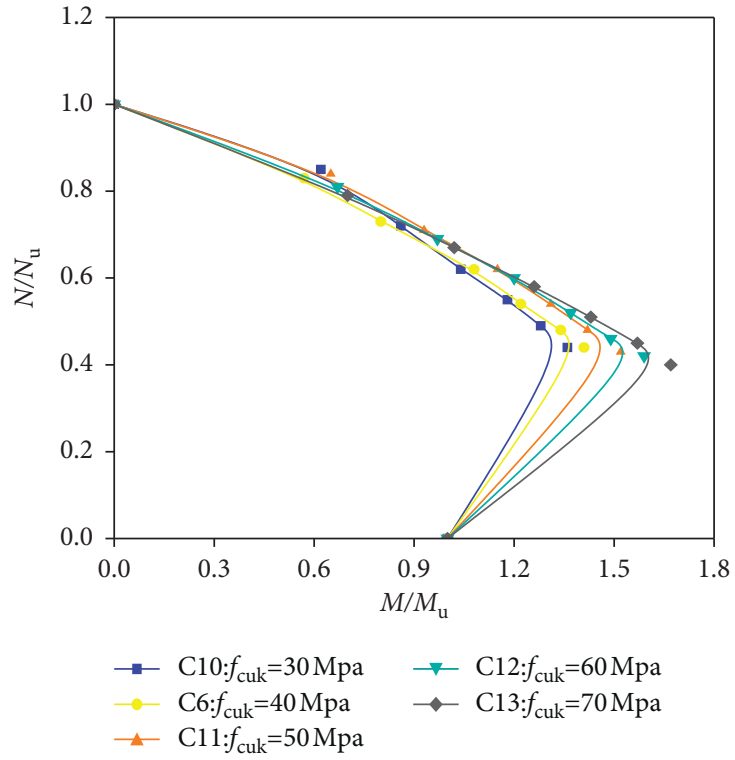

(a)

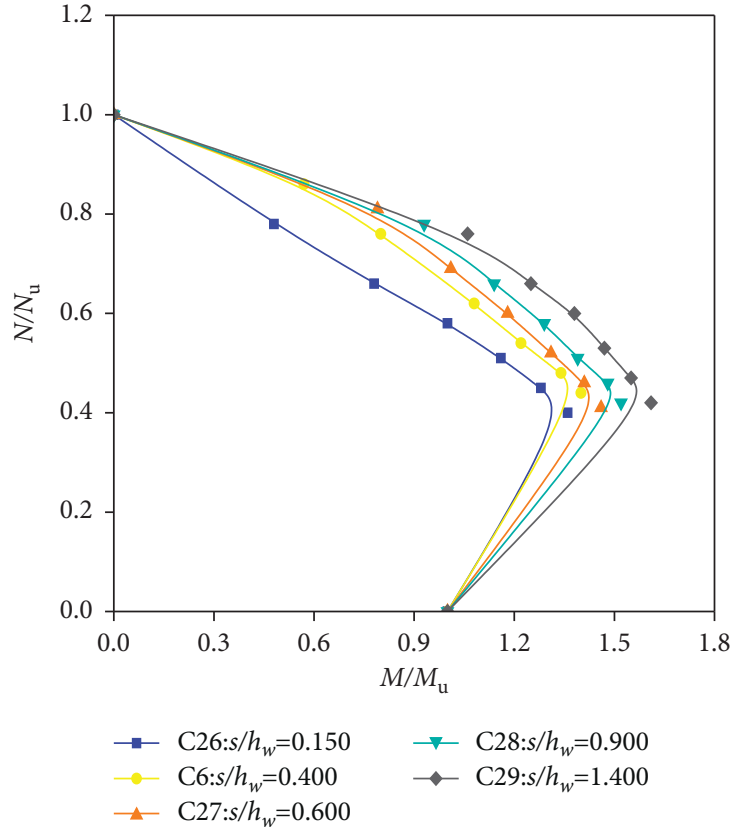

(c)

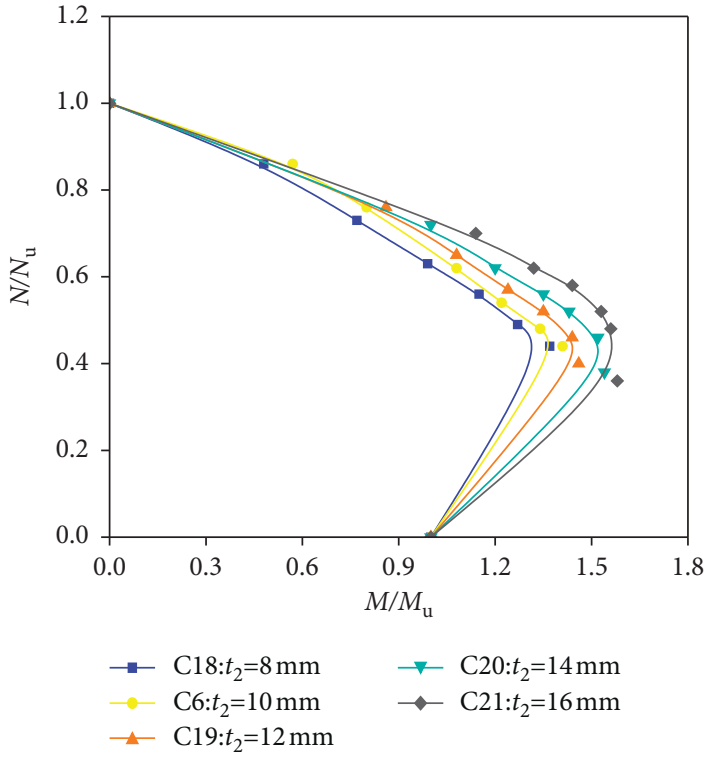

(b)

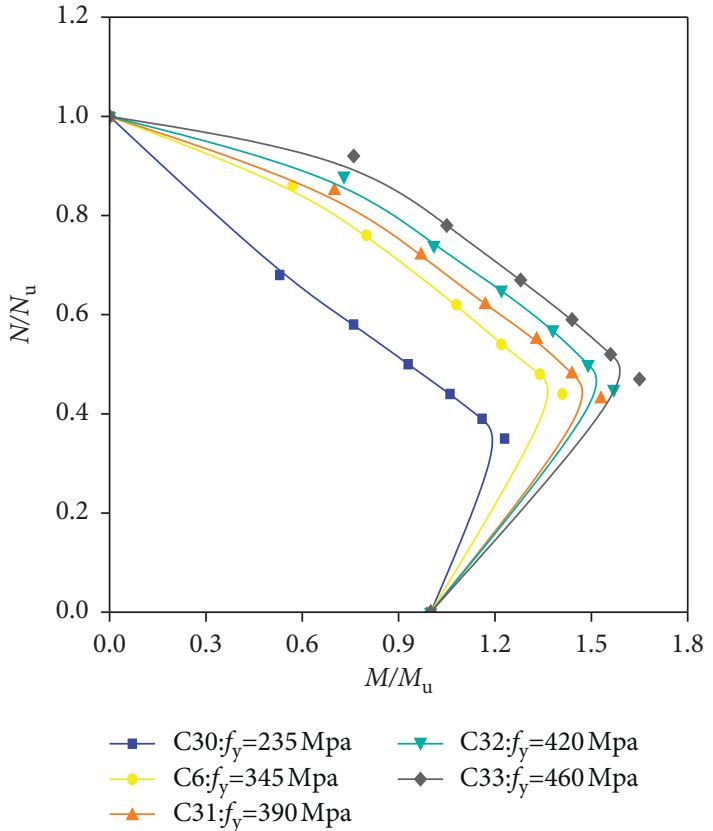

(d)

FiguRE 11: Comparisons of $N / N_{\mathrm{u}}-M / M_{\mathrm{u}}$ curves of STHCCs with different parameters. (a) $f_{\text {cuk }}$. (b) $t_{2}$. (c) $s / h_{\mathrm{w}}$. (d) $f_{\mathrm{y}^{\text {. }}}$.

When the load reaches $0.9 N_{\mathrm{u}}$, the deflection begins to rapidly increase, and eventually, the column destroys. The development regularity of the $H-\Delta$ curves of the STHCCs subjected to eccentrical compression is obtained, which is consistent with the development regularity of the ordinary square CFST columns under eccentrical compression [29].

6.2. Strain Distribution on Sections. Taking STHCC-1, STHCC-2, STHCC-3, STHCC-4, and STHCC-5 as representative examples, the longitudinal strain distribution of the mid-span section of the specimens under eccentrical compression is computed, as shown in Figure 13. During the loading process, the longitudinal strain of the mid-span section conforms to the plane-section assumption. At the early stage of the loading, namely, the elastic working stage, the longitudinal strain of the mid-span section is in good agreement with the plane-section assumption, which shows that the steel tube coordinated with the core concrete $[30,31]$.

When the load reaches $0.9 N_{\mathrm{u}}$, the steel tube in the compression side yields firstly, and the obvious bulging appears on steel tube, simultaneously the concrete is crushed, which indicates that both cannot work in 


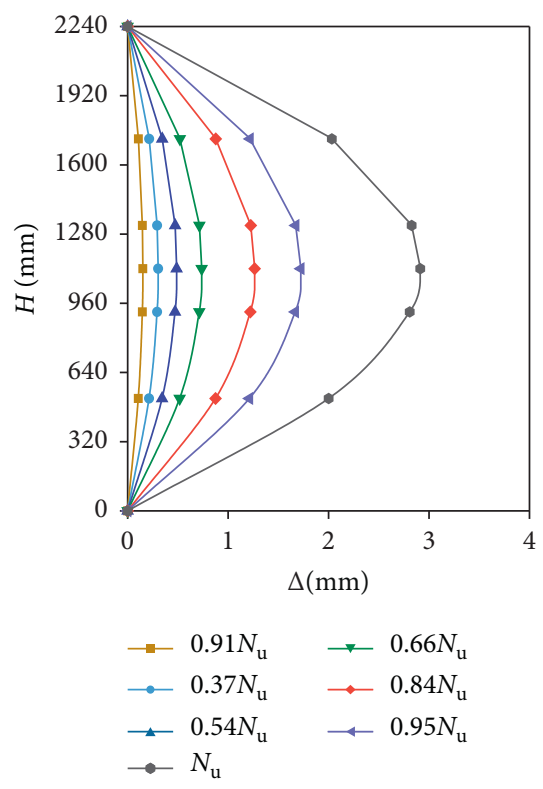

(a)

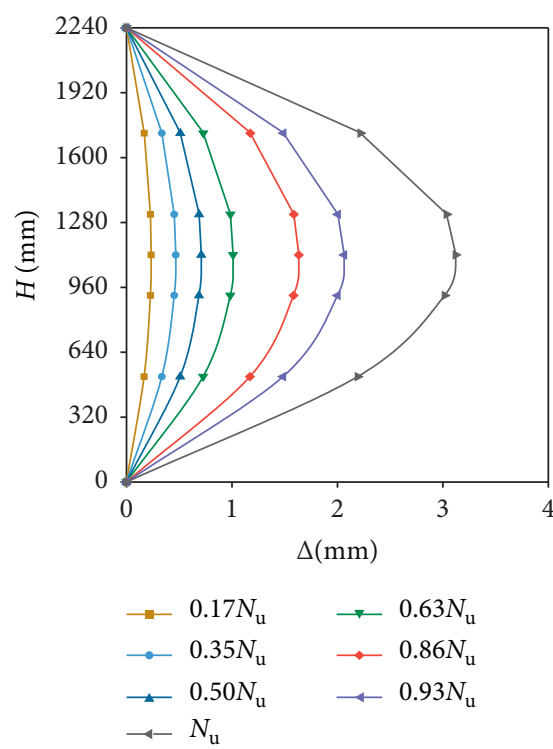

(d)
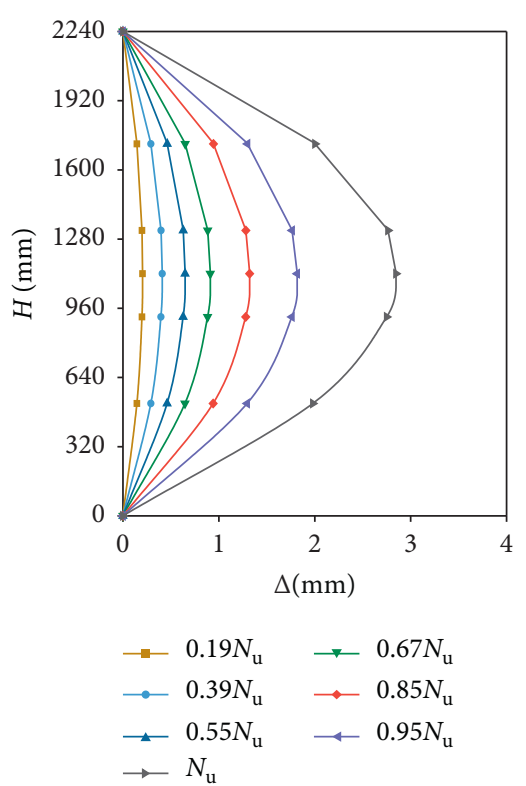

(b)
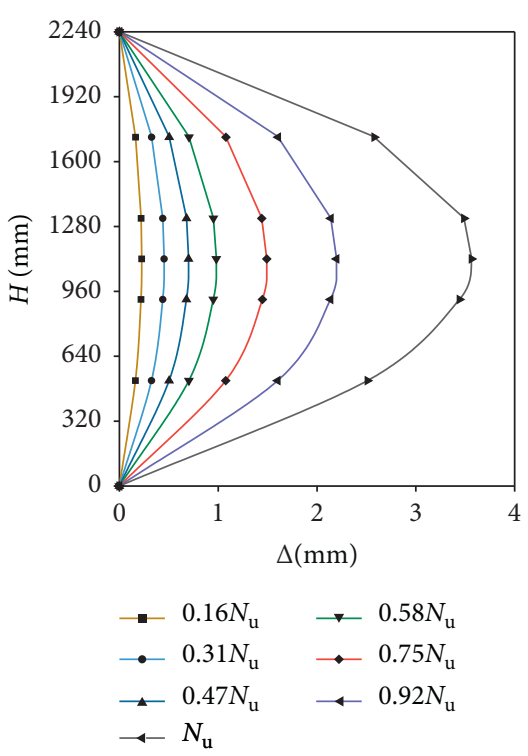

(e)

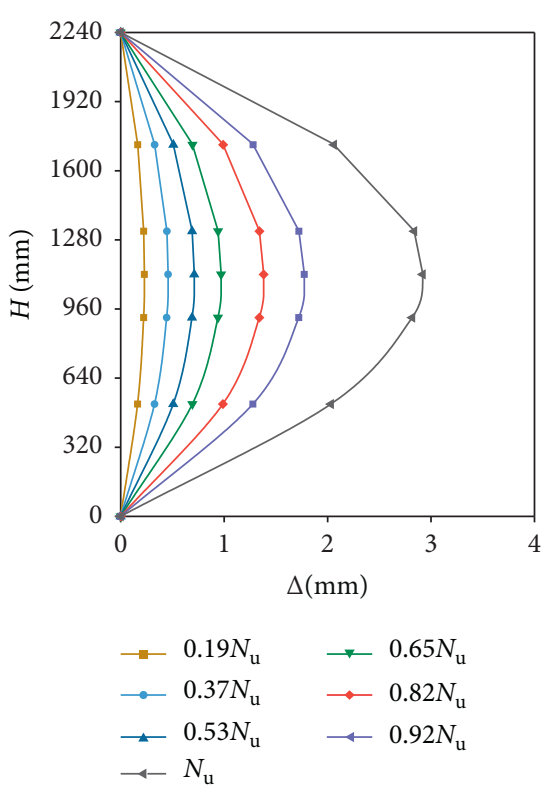

(c)

FIGURE 12: Comparisons of $H-\Delta$ curves of 5 specimens with different eccentricity. (a) STHCC-1. (b) STHCC-2. (c) STHCC-3. (d) STHCC-4. (e) STHCC-5.

coordination with each other. It is also found that with the increase in the eccentricity, the neutral axis of the mid-span section moves to the loading point gradually.

6.3. Load-Strain Curves. Figure 14 shows the load $(N)$ versus strain $(\varepsilon)$ relationships of point $A$ and point $E$ of specimen STHCC-1, and it can be seen from Figure 14 that at the initial stage of the loading, the strain and load of the tension and compression zone of STHCCs increase proportionally with the increase in the load. During the loading process, the longitudinal strain of the compression zone is greater than that of the tension side under the same load. When the load reaches about $95 \%$ of the ultimate load, the compression side of the steel tube yields firstly, and the mutual coordination between the steel tube and the core concrete is destroyed, eventually the overall specimen is bent and unstable. The stress cloud diagram of each part of specimen STHCC-1 is illustrated in Figure 15.

\section{Eccentric Compression Bearing Capacity of Full-Scale STHCCs}

The simplified calculation method on eccentrical compression bearing capacity for reduced-scale STHCCs has been proposed by Ji et al. [15], which can be expressed as (3). The specific meaning of variables is illustrated in reference [15]. 

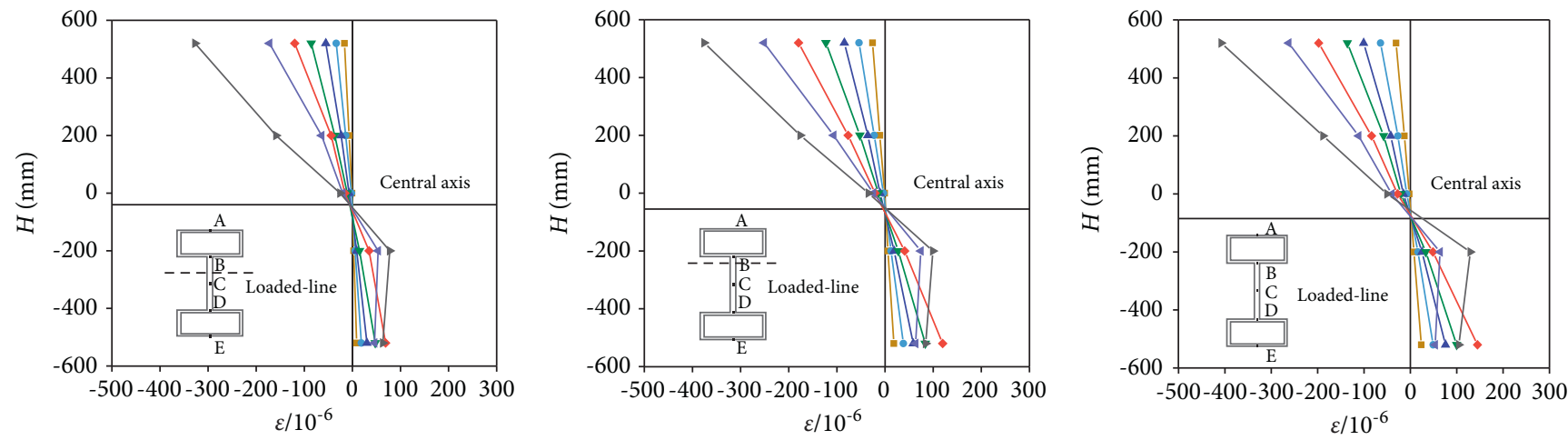

$$
\begin{aligned}
& \multimap 0.19 N_{\mathrm{u}} \quad \longrightarrow 0.66 N_{\mathrm{u}} \\
& \rightarrow 0.37 N_{\mathrm{u}} \quad \longrightarrow 0.84 N_{\mathrm{u}} \\
& \longrightarrow 0.54 N_{\mathrm{u}} \quad \multimap 0.95 N_{\mathrm{u}} \\
& \rightarrow N_{\mathrm{u}}
\end{aligned}
$$

(a)

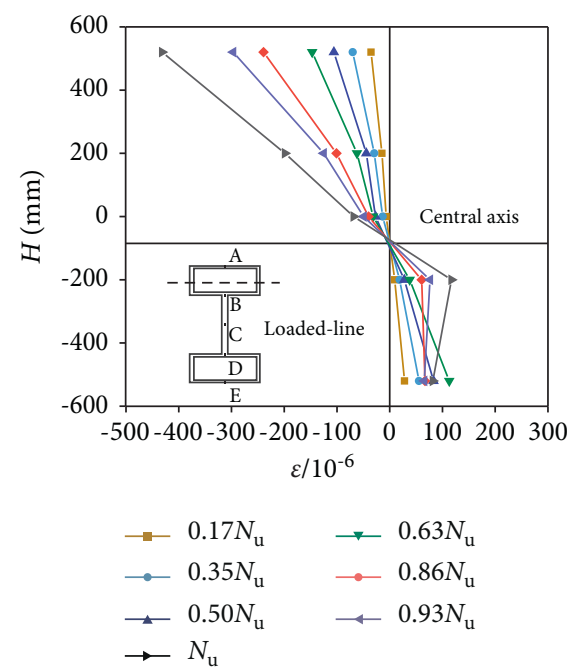

(d)

$$
\begin{aligned}
& \multimap 0.19 N_{\mathrm{u}} \quad \longrightarrow 0.67 N_{\mathrm{u}} \\
& \multimap 0.39 N_{\mathrm{u}} \quad \multimap 0.85 N_{\mathrm{u}} \\
& \multimap 0.55 N_{\mathrm{u}} \quad \longleftarrow 0.95 N_{\mathrm{u}} \\
& \rightarrow N_{\mathrm{u}}
\end{aligned}
$$

(b)

(c)

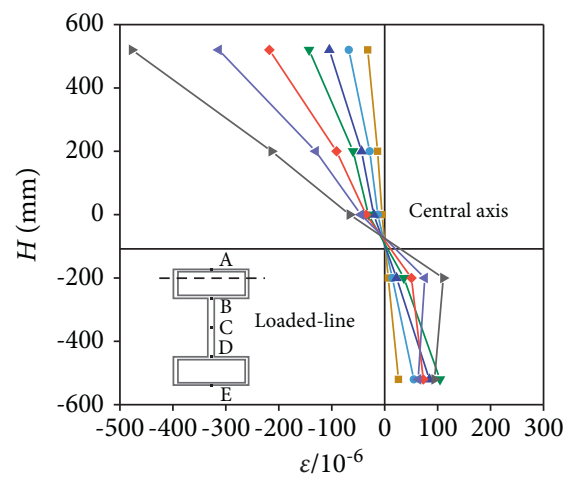

$$
\begin{aligned}
& \rightarrow 0.16 N_{\mathrm{u}} \quad \rightarrow 0.58 N_{\mathrm{u}} \\
& \rightarrow 0.31 N_{\mathrm{u}} \quad \longrightarrow 0.75 N_{\mathrm{u}} \\
& \multimap 0.47 N_{\mathrm{u}} \quad \hookrightarrow 0.92 N_{\mathrm{u}} \\
& \rightarrow-N_{\mathrm{u}}
\end{aligned}
$$

$$
\begin{aligned}
& \multimap 0.19 N_{\mathrm{u}} \quad \longrightarrow 0.65 N_{\mathrm{u}} \\
& \rightarrow 0.37 N_{\mathrm{u}} \longrightarrow 0.82 N_{\mathrm{u}} \\
& \hookrightarrow 0.53 N_{\mathrm{u}} \quad \longleftarrow 0.92 N_{\mathrm{u}} \\
& \rightarrow N_{\mathrm{u}}
\end{aligned}
$$

FIGURE 13: Longitudinal strain distribution of mid-span section of specimens with different eccentricity. (a) STHCC-1. (b) STHCC-2. (c) STHCC-3. (d) STHCC-4. (e) STHCC-5.

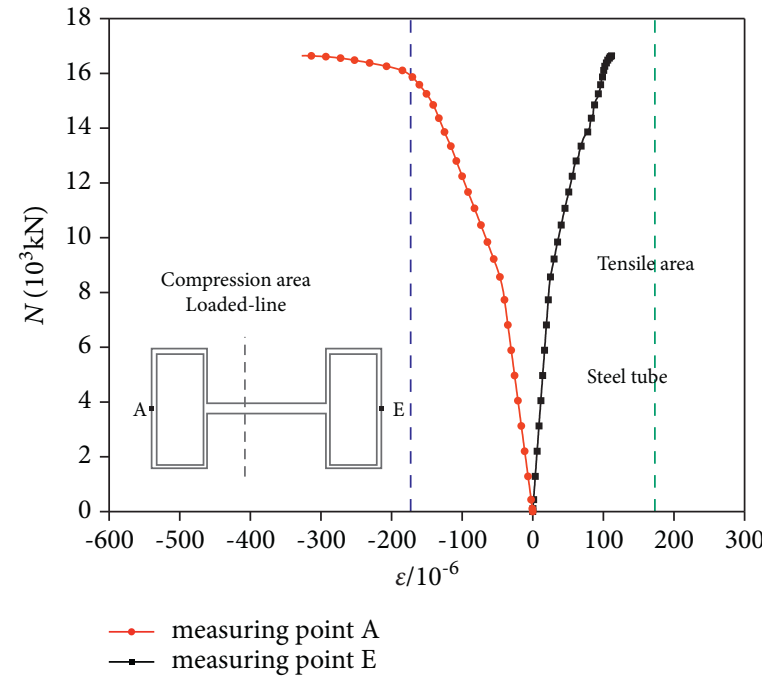

(a)

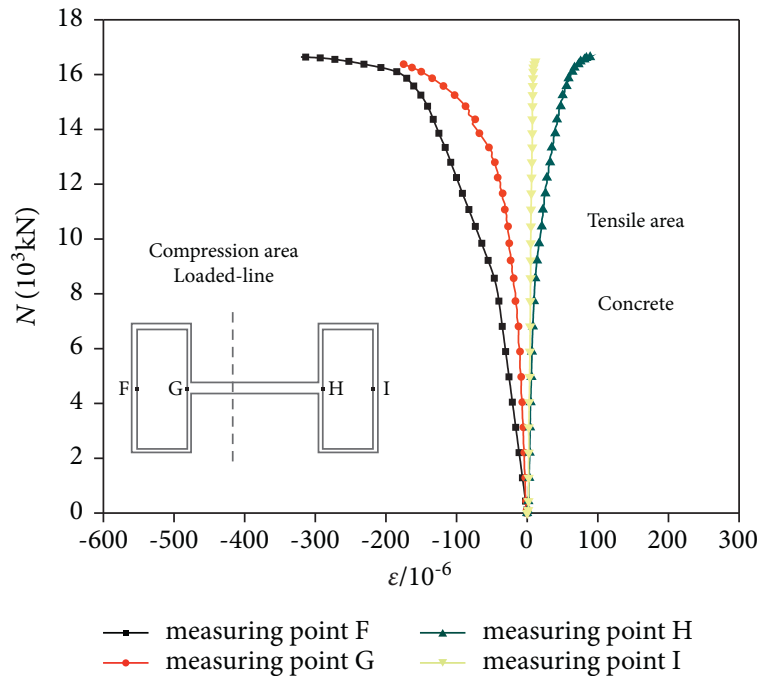

(b)

Figure 14: $N-\varepsilon$ curves for STHCC-1. (a) $N-\varepsilon$ curves for steel tube. (b) $N-\varepsilon$ curves for concrete. 


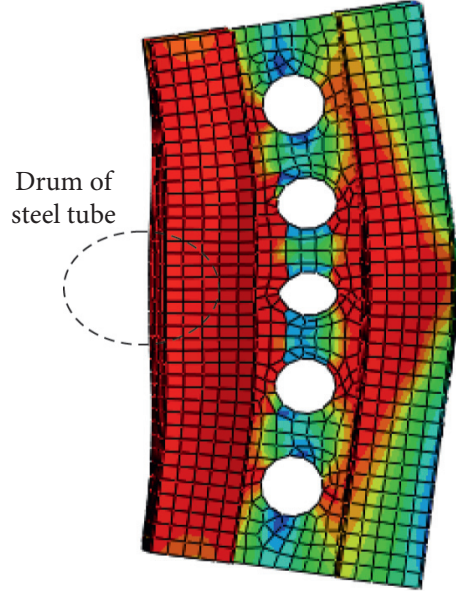

(a)

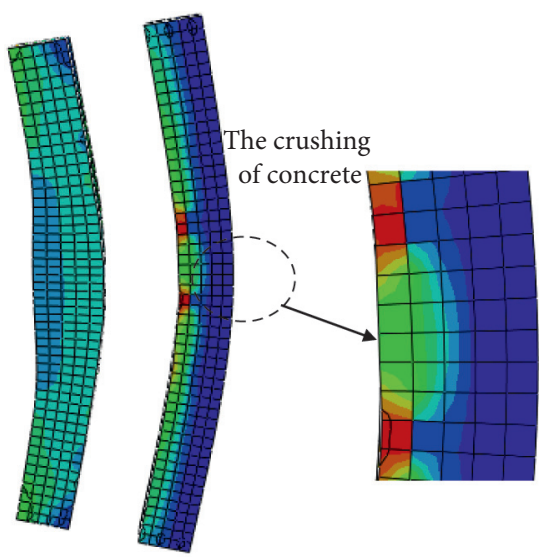

(b)

FIGURE 15: Stress cloud diagram of parts for specimen STHCC-1 in a state of failure. (a) The deformation of steel tube. (b) The deformation of concrete.

$$
N_{c}^{c}=\varphi_{e} \varphi_{1} \varphi_{f_{c k}} \varphi_{t_{1}} N_{u}
$$

Equation (3) is adopted to calculate the eccentrical compression bearing capacity $\left(N_{c}^{c}\right)$ of 33 full-scale specimens, and the dispersion comparison between $N_{c}^{c}$ and $N_{a}$ for 33 specimens is shown in Figure 16. As can be seen in Figure 16, the maximum error is $43.24 \%$. It is noteworthy that the calculation formula of eccentrical compression bearing capacity obtained based on the reduced-scale model has certain limitations; thus, it is not suitable for calculating the eccentrical compression bearing capacity of full-scale composite columns. So the calculation formula of eccentrical compression bearing capacity of full-scale composite columns needs to be put forward.

The equation of the $N / N_{\mathrm{u}}-M / M_{\mathrm{u}}$ curves for CFST composite columns proposed by $\mathrm{Han}<\mathrm{u}>[32,33]</ \mathrm{u}>$ can be expressed as follows:

$$
\begin{cases}\frac{N}{N_{u}}+a\left(\frac{M}{M_{u}}\right)=1, & \left(\frac{N}{N_{u}} \geq 2 \eta_{0}\right), \\ -b\left(\frac{N}{N_{u}}\right)^{2}-c\left(\frac{N}{N_{u}}\right)+\left(\frac{M}{M_{u}}\right)=1, & \left(\frac{N}{N_{u}}<2 \eta_{0}\right),\end{cases}
$$

where $a=1-2 \eta_{0}, b=\left(1-\xi_{0}\right) / \eta_{0}^{2}, c=2\left(\xi_{0}-1\right) / \eta_{0}$, and the significance of physical variables can be found in references [32, 33].

According to the unified theory deduced by Han [32], the axial compression capacity $\left(N_{u}\right)$ on bearing and flexural bearing capacity $\left(M_{u}\right)$ of CFST columns can be obtained, which are given by

$$
\begin{aligned}
& N_{u}=f_{s c y} A_{s c}, \\
& M_{u}=\gamma_{m} W_{s c m} f_{s c y},
\end{aligned}
$$

where $f_{s c y}=(1.18+0.64 \xi) \times f_{c k}, A_{s c}=A_{s}+A_{c}, \xi=A_{s} \times$ $f_{y} / A_{c} \times f_{c k}, \quad \gamma_{m}=1.04+0.48 \ln (\xi+0.1), \quad$ and $\quad W_{s c m}=$ $(2 I / h)$. The significance of physical variables is shown in reference [32].

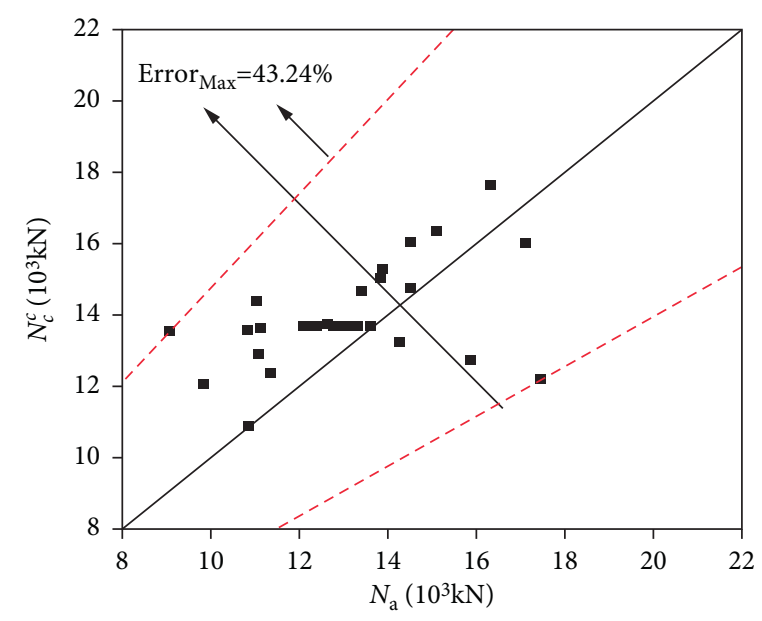

Figure 16: Comparison between $N_{c}^{c}$ and $N_{a}$.

Considering the influence of the eccentricity, the slenderness ratio, the cubic compressive strength of concrete, the thickness of steel tube flange, the thickness of honeycombed steel web, diameter-depth ratio, space-depth, and the yield strength of the steel tube on the mechanical behavior of fullscale STHCCs, the bias stability coefficient $(\varphi)$ [34] is subsequently introduced, and the influence of second-order bending moment [34] of the medium-long columns is considered. The related equation of $N / N_{\mathrm{u}}-M / M_{\mathrm{u}}$ curves is summarized as follows:

$$
\begin{cases}\frac{N}{\varphi N_{u}}+\frac{a}{d}\left(\frac{M}{M_{u}}\right)=1, & \left(\frac{N}{N_{u}} \geq 2 \eta_{0}\right), \\ -b\left(\frac{N}{N_{u}}\right)^{2}-c\left(\frac{N}{N_{u}}\right)+\frac{1}{d}\left(\frac{M}{M_{u}}\right)=1, & \left(\frac{N}{N_{u}}<2 \eta_{0}\right),\end{cases}
$$

where $\quad \mathrm{d}=1-0.25 N / N_{E}, \quad N_{E}=N_{u} \pi^{2} E_{s c} / \lambda^{2} f_{y}, \quad E_{s c}=$ $f_{s c p} / \varepsilon_{s c p}$, and $\quad f_{s c p}=\left[0.263 f_{y} / 235+0.365 \times\right.$ 


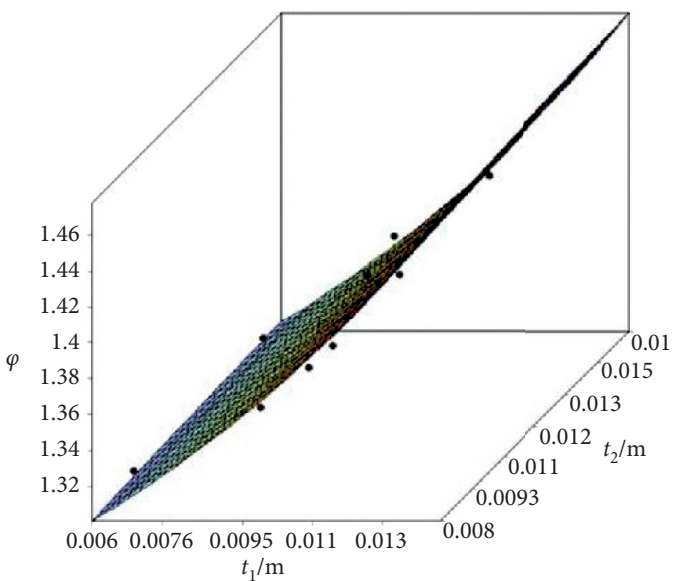

(a)

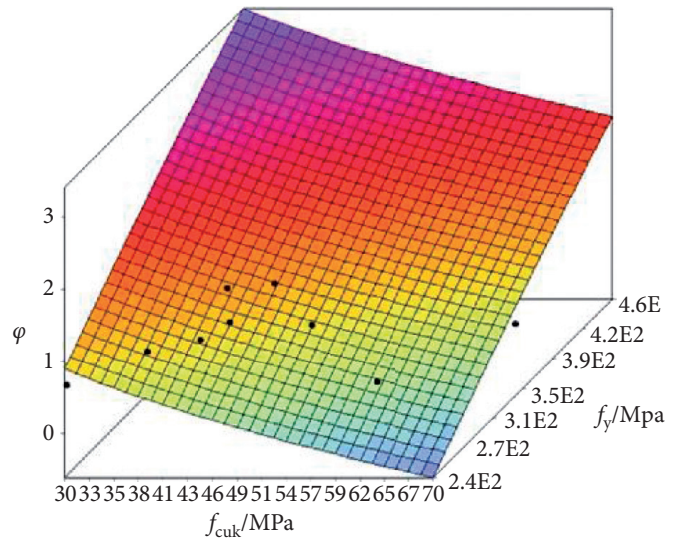

(c)

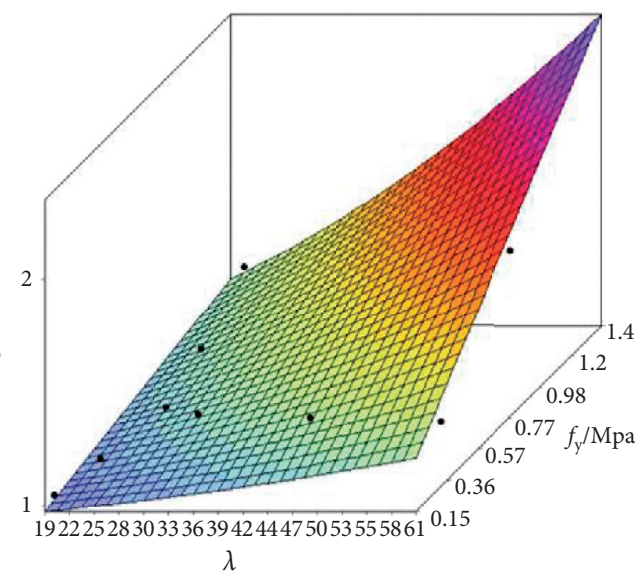

(b)

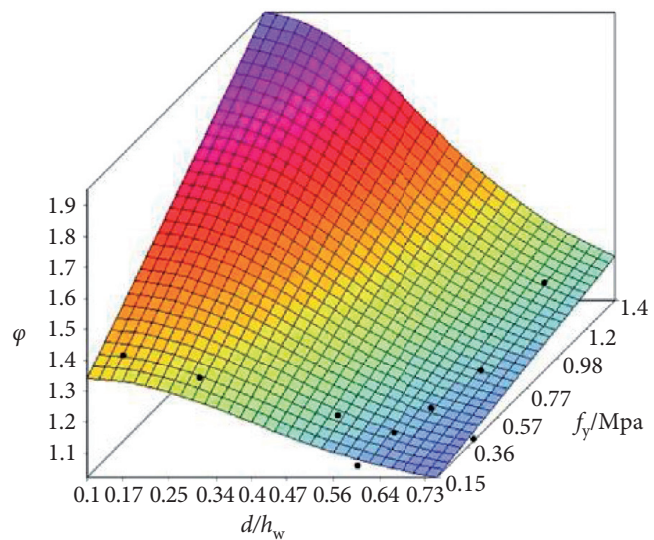

(d)

Figure 17: Effects of different parameters on $\varphi$. (a) $t_{1}$ and $t_{2}$. (b) $\lambda$ and $e$. (c) $f_{\text {cuk }}$ and $f_{\mathrm{y}}$. (d) $d / h_{\mathrm{w}}$ and $s / h_{\mathrm{w}}$.

TABle 3: The comparison between $N_{c}$ and $N_{a}$.

\begin{tabular}{|c|c|c|c|c|c|c|c|c|c|c|c|}
\hline Specimens & $t_{1}(\mathrm{~mm})$ & $t_{2}(\mathrm{~mm})$ & $\lambda$ & $E(\mathrm{~mm})$ & $d / h_{\mathrm{w}}$ & $\begin{array}{l}s / \\
h_{\mathrm{w}}\end{array}$ & $N_{c}^{c}\left(10^{3} \mathrm{kN}\right)$ & $N_{a}\left(10^{3} \mathrm{kN}\right)$ & $N_{c}\left(10^{3} \mathrm{kN}\right)$ & $\begin{array}{c}\left|N_{a}-N_{c}^{c} / N_{c}^{c}\right| \\
(\%)\end{array}$ & $\left|N_{a}-N_{c} / N_{c}\right|(\%)$ \\
\hline STHCC-1 & 8 & 10 & 19.40 & 80 & 0.6 & 0.4 & 15.99 & 17.09 & 16.57 & 6.88 & 3.14 \\
\hline STHCC-2 & 8 & 10 & 19.40 & 160 & 0.6 & 0.4 & 14.74 & 14.53 & 14.25 & 1.42 & 1.96 \\
\hline STHCC-3 & 8 & 10 & 19.40 & 240 & 0.6 & 0.4 & 13.73 & 12.62 & 12.47 & 8.08 & 1.20 \\
\hline STHCC-4 & 8 & 10 & 19.40 & 320 & 0.6 & 0.4 & 12.85 & 11.07 & 11.06 & 13.85 & 0.09 \\
\hline STHCC-5 & 8 & 10 & 19.40 & 400 & 0.6 & 0.4 & 12.05 & 9.83 & 9.93 & 18.42 & 1.01 \\
\hline STHCC-6 & 8 & 10 & 26.33 & 240 & 0.6 & 0.4 & 13.69 & 12.11 & 12.24 & 11.54 & 1.06 \\
\hline STHCC-7 & 8 & 10 & 40.18 & 240 & 0.6 & 0.4 & 13.61 & 11.13 & 11.81 & 18.22 & 5.76 \\
\hline STHCC-8 & 8 & 10 & 54.04 & 240 & 0.6 & 0.4 & 13.54 & 10.84 & 10.16 & 19.94 & 6.69 \\
\hline STHCC-9 & 8 & 10 & 60.97 & 240 & 0.6 & 0.4 & 13.50 & 9.06 & 9.32 & 32.89 & 2.79 \\
\hline $\begin{array}{l}\text { STHCC- } \\
10\end{array}$ & 8 & 10 & 26.33 & 240 & 0.6 & 0.4 & 14.38 & 11.06 & 11.01 & 23.09 & 0.45 \\
\hline $\begin{array}{l}\text { STHCC- } \\
11\end{array}$ & 8 & 10 & 26.33 & 240 & 0.6 & 0.4 & 13.22 & 14.28 & 14.27 & 8.02 & 0.07 \\
\hline $\begin{array}{l}\text { STHCC- } \\
12\end{array}$ & 8 & 10 & 26.33 & 240 & 0.6 & 0.4 & 12.72 & 15.87 & 15.91 & 24.76 & 0.25 \\
\hline $\begin{array}{l}\text { STHCC- } \\
13\end{array}$ & 8 & 10 & 26.33 & 240 & 0.6 & 0.4 & 12.18 & 17.45 & 17.36 & 43.24 & 0.52 \\
\hline $\begin{array}{l}\text { STHCC- } \\
14\end{array}$ & 6 & 10 & 26.33 & 240 & 0.6 & 0.4 & 12.32 & 11.37 & 12.11 & 7.71 & 6.11 \\
\hline
\end{tabular}


TABLE 3: Continued.

\begin{tabular}{|c|c|c|c|c|c|c|c|c|c|c|c|}
\hline Specimens & $t_{1}(\mathrm{~mm})$ & $t_{2}(\mathrm{~mm})$ & $\lambda$ & $E(\mathrm{~mm})$ & $d / h_{\mathrm{w}}$ & $\begin{array}{l}s / \\
h_{\mathrm{w}}\end{array}$ & $N_{c}^{c}\left(10^{3} \mathrm{kN}\right)$ & $N_{a}\left(10^{3} \mathrm{kN}\right)$ & $N_{c}\left(10^{3} \mathrm{kN}\right)$ & $\begin{array}{c}\left|N_{a}-N_{c}^{c} / N_{c}^{c}\right| \\
(\%)\end{array}$ & $\left|N_{a}-N_{c} / N_{c}\right|(\%)$ \\
\hline $\begin{array}{l}\text { STHCC- } \\
15\end{array}$ & 10 & 10 & 26.33 & 240 & 0.6 & 0.4 & 15.03 & 13.85 & 13.93 & 7.85 & 0.57 \\
\hline $\begin{array}{l}\text { STHCC- } \\
16\end{array}$ & 12 & 10 & 26.33 & 240 & 0.6 & 0.4 & 16.34 & 15.10 & 15.49 & 7.59 & 2.52 \\
\hline $\begin{array}{l}\text { STHCC- } \\
17\end{array}$ & 14 & 10 & 26.33 & 240 & 0.6 & 0.4 & 17.63 & 16.32 & 17.22 & 7.43 & 5.23 \\
\hline $\begin{array}{l}\text { STHCC- } \\
18\end{array}$ & 8 & 8 & 26.33 & 240 & 0.6 & 0.4 & 13.69 & 12.29 & 12.61 & 10.23 & 2.54 \\
\hline $\begin{array}{l}\text { STHCC- } \\
19\end{array}$ & 8 & 12 & 26.33 & 240 & 0.6 & 0.4 & 13.69 & 12.93 & 12.73 & 5.55 & 1.57 \\
\hline $\begin{array}{l}\text { STHCC- } \\
20\end{array}$ & 8 & 14 & 26.33 & 240 & 0.6 & 0.4 & 13.69 & 13.14 & 12.63 & 4.02 & 4.04 \\
\hline STHCC-21 & 8 & 16 & 26.33 & 240 & 0.6 & 0.4 & 13.69 & 13.34 & 12.64 & 2.56 & 5.54 \\
\hline $\begin{array}{l}\text { STHCC- } \\
22\end{array}$ & 8 & 10 & 26.33 & 240 & 0.10 & 0.4 & 13.69 & 13.60 & 13.41 & 0.66 & 1.42 \\
\hline $\begin{array}{l}\text { STHCC- } \\
23\end{array}$ & 8 & 10 & 26.33 & 240 & 0.3 & 0.4 & 13.69 & 13.29 & 13.27 & 2.92 & 0.15 \\
\hline $\begin{array}{l}\text { STHCC- } \\
24\end{array}$ & 8 & 10 & 26.33 & 240 & 0.475 & 0.4 & 13.69 & 12.96 & 12.93 & 5.33 & 0.23 \\
\hline $\begin{array}{l}\text { STHCC- } \\
25\end{array}$ & 8 & 10 & 26.33 & 240 & 0.75 & 0.4 & 13.69 & 12.31 & 12.24 & 10.08 & 0.57 \\
\hline $\begin{array}{l}\text { STHCC- } \\
26\end{array}$ & 8 & 10 & 26.33 & 240 & 0.6 & 0.15 & 13.69 & 12.41 & 12.47 & 9.35 & 0.48 \\
\hline $\begin{array}{l}\text { STHCC- } \\
27\end{array}$ & 8 & 10 & 26.33 & 240 & 0.6 & 0.6 & 13.69 & 12.78 & 12.72 & 6.65 & 0.47 \\
\hline $\begin{array}{l}\text { STHCC- } \\
28\end{array}$ & 8 & 10 & 26.33 & 240 & 0.6 & 0.9 & 13.69 & 12.94 & 12.89 & 5.48 & 0.39 \\
\hline $\begin{array}{l}\text { STHCC- } \\
29\end{array}$ & 8 & 10 & 26.33 & 240 & 0.6 & 1.4 & 13.69 & 13.12 & 13.17 & 4.16 & 0.38 \\
\hline $\begin{array}{l}\text { STHCC- } \\
30\end{array}$ & 8 & 10 & 26.33 & 240 & 0.6 & 0.4 & 10.86 & 10.86 & 11.79 & 0 & 7.89 \\
\hline STHCC-31 & 8 & 10 & 26.33 & 240 & 0.6 & 0.4 & 14.67 & 13.40 & 13.34 & 8.66 & 0.45 \\
\hline $\begin{array}{l}\text { STHCC- } \\
32\end{array}$ & 8 & 10 & 26.33 & 240 & 0.6 & 0.4 & 15.27 & 13.88 & 13.71 & 9.10 & 1.24 \\
\hline $\begin{array}{l}\text { STHCC- } \\
33\end{array}$ & 8 & 10 & 26.33 & 240 & 0.6 & 0.4 & 16.03 & 14.51 & 14.06 & 9.48 & 3.20 \\
\hline
\end{tabular}

$\left.30 / f_{c u}+0.104\right] \times f_{s c y}$. The significance of physical variables is shown in reference [34]. follows:

The expression of $\varphi$ is obtained by statistical regression as

$$
\varphi=0.93+\frac{-14 f_{c u k}^{0.32}+t_{2}^{0.22}+2.78 s / h_{w}+f_{y}^{0.67}}{397 \lambda^{1.38}-106 t_{1}+10\left(d / h_{w}\right)^{3}} \times e .
$$

The effects of different parameters on $\varphi$ are illustrated in Figure 17.

According to the (6), the eccentrical compression bearing capacity $\left(N_{c}\right)$ for 33 STHCCs can be calculated as shown in Table 3. By comparison, it can be seen from Figure 18 that the maximum error between $N_{c}$ and $N_{a}$ is $7.89 \%$, which shows that both are in good agreement and can meet the requirements in actual engineering.

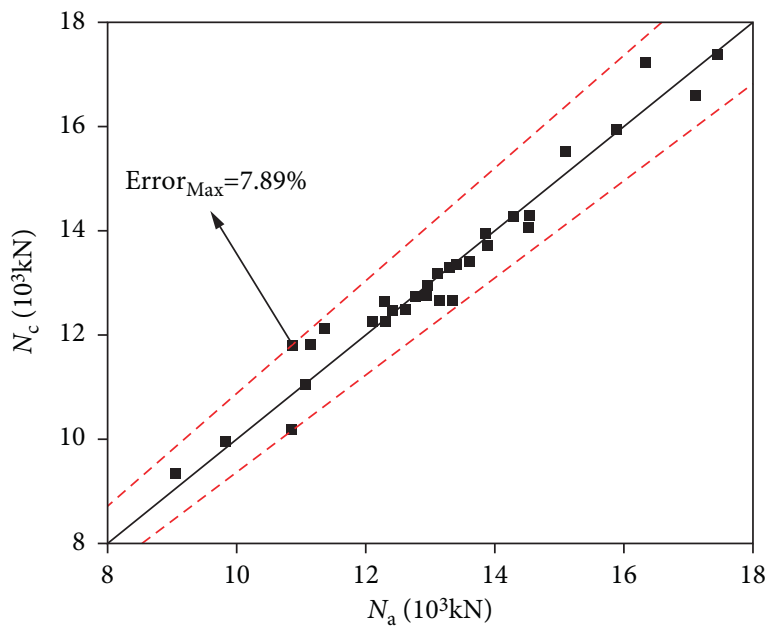

Figure 18: Comparison between $N_{c}$ and $N_{a}$. 


\section{Conclusions}

The eccentrical compression behavior analysis of 33 fullscale STHCCs was studied. The conclusions can be drawn as follows.

Based on the nonlinear constitutive model of concrete and simplified constitutive model of steel, the load-vertical displacement curves and load-lateral deflection curves of 15 square CFST columns were obtained by ABAQUS software. By comparison with the existing test data, both were in good agreement, which could verify the rationality of the material constitutive model and FE modeling method.

The development regularity of lateral deflection curves for full-scale STHCCs is consistent with that of lateral deflection curves for CFST columns, and the maximum deflection appears at the mid-span sections of the specimens. The stress distribution along the cross-sectional height of the mid-span sections for full-scale STHCCs subjected to eccentrical compression basically conforms to the planesection assumption.

The influence of parameters on eccentrical compression bearing capacity and lateral deflection is systematically investigated. It can be concluded that with the increase in $e, \lambda$, and $d / h_{\mathrm{w}}$, the eccentrical compression bearing capacity of specimens decreases gradually, whereas the eccentrical compression bearing capacity of specimens increases significantly with the increase in $f_{\text {cuk }}, t_{1}, t_{2}, s / h_{\mathrm{w}}$, and $f_{\mathrm{y}}$. It can be found that the lateral deflection of the mid-span section decreases gradually with the increase in $e, f_{\text {cuk }}, t_{1}$, and $d / h_{\mathrm{w}}$, whereas the lateral deflection of the mid-span section gradually increases as $\lambda, t_{2}, s / h_{\mathrm{w}}$, and $f_{\mathrm{y}}$ increase.

The calculation formula on eccentrical compression bearing capacity for STHCCs is proposed by statistical regression.

\section{Data Availability}

The data used to support the findings of this study are included within the article.

\section{Conflicts of Interest}

The authors declare that they have no conflicts of interest.

\section{Acknowledgments}

The authors are grateful for the financial support received from the Social Science Foundation of Hebei Province (Grant no. HB20GL055).

\section{References}

[1] J. Ji, Z. C. Xu, L. Q. Jiang et al., "Nonlinear buckling analysis of H-type honeycombed composite column with rectangular concrete-filled steel tube flanges," International Journal of Steel Structures, vol. 18, no. 4, pp. 1153-1166, 2018.

[2] S. Jayaganesh, J. R. Murugadoss, G. G. Prabhu, and J. Jegan, "Effects of concentrical partial (local) compression on the structural behavior of concrete filled steel tubular column,"
Advances in Materials Science and Engineering, vol. 2015, Article ID 491038, 9 pages, 2015.

[3] M. Ahmed, Q. Q. Liang, V. I. Patel, and M. N. S. Hadi, "Localglobal interaction buckling of square high strength concretefilled double steel tubular slender beam-columns," ThinWalled Structures, vol. 143, Article ID 106244, 2019.

[4] G. Vatulia, M. Rezunenko, D. Petrenko, Y. Balaka, and Y. Orel, "A statistical method for predicting the eccentric load capacity of rectangular concrete filled steel tubular columns," MATEC Web of Conferences, vol. 313, Article ID 00031, 2020.

[5] Y. Feng, L. L. Yin, Y. Fang, and J. J. Jiang, "Mechanical behavior of recycled coarse aggregates self-compacting concrete-filled steel tubular columns under eccentric compression," Structural Concrete, vol. 20, no. 6, pp. 2000-2014, 2019.

[6] Y. J. Li, W. H. Liu, and H. Han, "Analytical behaviour of rectangular concrete filled stainless steel tubular columns under Bi-axial eccentric compression," Materials Science and Engineering, vol. 490, no. 3, Article ID 032004, 2019.

[7] B. Rong, C. X. Feng, R. Y. Zhang, G. C. You, and R. Liu, "Compression-bending behavior of L-shaped column composed of concrete filled square steel tubes under eccentric compression," International Journal of Steel Structures, vol. 17, no. 1, pp. 325-337, 2017.

[8] Y. Sui, Y. Q. Tu, Q. Q. Guo, J. F. Zhang, and F. Ke, "Study on the behavior of multi-cell composite T-shaped concrete-filled steel tubular columns subjected to compression under biaxial eccentricity," Journal of Constructional Steel Research, vol. 159, pp. 215-230, 2019.

[9] Z. P. Chen, J. Zhou, C. G. Jing, and Q. H. Tan, "Mechanical behavior of spiral stirrup reinforced concrete filled square steel tubular columns under compression," Engineering Structures, vol. 226, pp. 215-230, 2020.

[10] F. Yu, P. C. Xu, Y. Fang, Y Zhang, and J. J. Jiang, "Stiffness analysis of recycled self-compacting concrete-filled circular steel tubular columns under eccentric compression," Advances In Civil Engineering, vol. 2019, Article ID 2749587, 15 pages, 2019.

[11] J. Ji, Z. C. Xu, W. F. Zhang et al., "Eigenvalue buckling analysis of $\mathrm{H}$ type honeycombed composite column with rectangular concrete-filled steel tube flanges," Journal of Northeast Petroleum University, vol. 41, no. 1, pp. 106-142, 2017.

[12] J. Ji, Z. C. Xu, L. Q. Jiang et al., "Nonlinear buckling analysis of H-type honeycombed composite column with rectangular concrete-filled steel tube flanges," Building Structure, vol. 48, no. 15 , pp. $50-55+70,2018$.

[13] Z. C. Xu, "Axial compression and stability behavior of H-type honeycombed column with concrete-filled steel tube flanges(STHCC)," Master Dissertation, Northeast Petroleum University, Daqing, China, 2018.

[14] J. Ji, Z. C. Xu, L. Q. Jiang, Y. C. Liu, D. Y. Yu, and M. M. Yang, "Experimental study on compression behavior of $\mathrm{H}$-shaped composite short column with rectangular CFST flanges and honeycombed steel web subjected to axial load," Journal of Building Structures, vol. 40, no. 9, pp. 63-73, 2019.

[15] J. Ji, L. Jiang, L. Q. Jiang, Y. F. Zhang, Z. C. Teng, and Y. C. Liu, "Mechanic behavior of $\mathrm{H}$ - type honeycomb composite columns with rectangular concrete-filled steel tubes subjected to eccentric load," Journal of Northeast Petroleum University, vol. 44, no. 4, pp. 121-132, 2020.

[16] L. H. Han, Concrete Filled Steel Tube Structure-Theory and Practice, Science Press, Beijing, China, 2007. 
[17] M. Pagoulatou, T. Sheehan, X. H. Dai, and D. Lam, "Finite element analysis on the capacity of circular concrete-filled double-skin steel tubular (CFDST) stub columns," Engineering Structures, vol. 72, pp. 102-112, 2014.

[18] L. Lam and J. G. Teng, "Design-oriented stress-strain model for FRP-confined concrete," Construction and Building Materials, vol. 17, no. 9, pp. 471-489, 2003.

[19] J. B. Mander, M. J. N. Priestley, and R. Park, "Theoretical stress-strain model for confined concrete," Journal of Structural Engineering, vol. 114, no. 8, pp. 1804-1826, 1988.

[20] J. R. Qian, L. R. Cheng, and D. L. Zhou, "Behavior of axially loaded concrete columns confined with ordinary hoops," Journal of Tsinghua University Science and Technology, vol. 10, pp. 1369-1373, 2002.

[21] GB 50010-2010, National Standard of the People's Republic of China Code for Design of Concrete Structures GB50010-2010, China Architecture \& Building Press, Beijing, China, 2010.

[22] X. L. Cao, L. M. Wu, and Z. M. Li, "Behaviour of steelreinforced concrete columns under combined torsion based on ABAQUS FEA," Engineering Structures, vol. 209, Article ID 109980, 2020.

[23] L. Wang, "Numerical analysis of the bonding behavior of steel fiber-concrete interface," Journal of water resources and architectural engineering, vol. 17, no. 2, pp. 56-60, 2019.

[24] B. Li, Y. C. Gao, B. Wang, and F. Zhang, "Research on the mechanics behavior of concrete-filled square steel tubular columns subjected to eccentric compression," Building Structure, vol. 40, no. S2, pp. 398-400, 2010.

[25] Y. S. Du, Z. H. Chen, Y. B. Wang, and J. Y. Richard Liew, "Ultimate resistance behavior of rectangular concrete-filled tubular beam-columns made of high-strength steel," Journal of Constructional Steel Research, vol. 133, pp. 418-433, 2017.

[26] Y. S. Du, Z. H. Chen, and M. X. Xiong, "Experimental behavior and design method of rectangular concrete-filled tubular columns using Q460 high-strength steel," Construction and Building Materials, vol. 125, pp. 856-872, 2016.

[27] Y. S. Du, Z. H. Chen, J. Y. Richard Liew, and M. X. Xiong, "Rectangular concrete-filled steel tubular beam-columns using high-strength steel: experiments and design," Journal of Constructional Steel Research, vol. 131, pp. 1-18, 2017.

[28] Y. S. Du, "Theoretical Analysis and Experimental Study on Rectangular Concrete-Filled Steel Tube Columns Using HighStrength Steel," Doctoral Dissertation, Tianjin University, Tianjin, China, 2017.

[29] T. Zhao and L. B. Yan, "Bearing capacity studies on square steel tube confined steel reinforced concrete column under eccentric load," Advances in Civil Engineering, vol. 2020, Article ID 4212049, 11 pages, 2020.

[30] K. Q. Yu, W. Mcgee, T. Y. Ng, H. Zhu, and V. C. Li, “3Dprintable engineered cementitious composites (3DP-ECC): fresh and hardened properties," Cement and Concrete Research, vol. 143, Article ID 106388, 2021.

[31] Z. W. Cai, F. C. Liu, J. T. Yu, K. Q. Yu, and L. K. Tian, "Development of ultra-high ductility engineered cementitious composites as a novel and resilient fireproof coating," Construction and Building Materials, vol. 288, Article ID 123090, 2021.

[32] L. H. Han and Y. F. Yang, Modern Concrete Filled Steel Tube Structure Technology, Architecture \& Building Press, Beijing, China, 2007.
[33] L. H. Han, C. Hou, and Y. X. Hua, "Concrete-filled steel tubes subjected to axial compression: life-cycle based behavior," Journal of Constructional Steel Research, vol. 170, Article ID 106063, 2020.

[34] Z.-B. Wang, Z. Tao, and Q. Yu, "Axial compressive behaviour of concrete-filled double-tube stub columns with stiffeners," Thin-Walled Structures, vol. 120, pp. 91-104, 2017. 